\title{
DNMT1-induced miR-378a-3p silencing promotes angiogenesis via the NF-KB signaling pathway by targeting TRAF1 in hepatocellular carcinoma
}

\author{
Bin Zhu ${ }^{1,2,3 \dagger}$, Jun-Jie Chen ${ }^{2 \dagger}$, Ying Feng ${ }^{1 \dagger}$, Jun-Ling Yang ${ }^{2}$, Hua Huang ${ }^{4}$, Wen Yuan Chung ${ }^{5}$, Yi-Lin Hu ${ }^{*}$ and
} Wan-Jiang Xue ${ }^{1 *}$

\begin{abstract}
Background: Angiogenesis plays an important role in the occurrence, development and metastasis of hepatocellular carcinoma (HCC). According to previous studies, miR-378a participates in tumorigenesis and tumor metastasis, but its exact role in HCC angiogenesis remains poorly understood.

Methods: qRT-PCR was used to investigate the expression of miR-378a-3p in HCC tissues and cell lines. The effects of miR-378a-3p on HCC in vitro and in vivo were examined by Cell Counting Kit-8 (CCK-8), Transwell, tube formation and Matrigel plug assays, RNA sequencing, bioinformatics, luciferase reporter, immunofluorescence and chromatin immunoprecipitation (ChIP) assays were used to detect the molecular mechanism by which miR-378a-3p inhibits angiogenesis.

Results: We confirmed that miR-378a-3p expression was significantly downregulated and associated with higher microvascular density (MVD) in HCC; miR-378a-3p downregulation indicated a short survival time in HCC patients. miR-378a-3p knockdown led to a significant increase in angiogenesis in vitro and in vivo. We found that miR-378a-3p directly targeted TNF receptor associated factor 1 (TRAF1) to attenuate NF-KB signaling, and then downregulated secreted vascular endothelial growth factor. DNA methyltransferase 1 (DNMT1)-mediated hypermethylation of miR$378 a-3 p$ was responsible for downregulating miR-378a-3p. Moreover, a series of investigations indicated that p65 initiated a positive feedback loop that could upregulate DNMT1 to promote hypermethylation of the miR-378a-3p promoter.
\end{abstract}

Conclusion: Our study indicates a novel DNMT1/miR-378a-3p/TRAF1/NF-KB positive feedback loop in HCC cells, which may become a potential therapeutic target for HCC.

Keywords: Angiogenesis, HCC, miR-378a-3p, TRAF1, DNA methylation

*Correspondence: hyl510@ntu.edu.cn; xuewanjiang@ntu.edu.cn ${ }^{\dagger}$ Bin Zhu, Jun-Jie Chen and Ying Feng contributed equally to this work. ${ }^{1}$ Department of General Surgery, Affiliated Hospital of Nantong University, 20 Xisi Street, Nantong 226001, Jiangsu, China

Full list of author information is available at the end of the article

\section{Background}

Hepatocellular carcinoma (HCC) is one of the most common digestive tract tumors in the world, with approximately 850,000 new cases and at least 780,000 related deaths annually [1]. With advancements in diagnostic techniques and the development of surgical strategies, such as hepatectomy, liver transplantation, local ablation original author(s) and the source, provide a link to the Creative Commons licence, and indicate if changes were made. The images or other third party material in this article are included in the article's Creative Commons licence, unless indicated otherwise in a credit line to the material. If material is not included in the article's Creative Commons licence and your intended use is not permitted by statutory regulation or exceeds the permitted use, you will need to obtain permission directly from the copyright holder. To view a copy of this licence, visit http://creativecommons.org/licenses/by/4.0/. The Creative Commons Public Domain Dedication waiver (http://creativeco mmons.org/publicdomain/zero/1.0/) applies to the data made available in this article, unless otherwise stated in a credit line to the data. 
therapy, and transarterial chemoembolization, the survival rate and quality of life of HCC patients have significantly improved; however, the five-year survival rate is still less than 30\% [2]. Angiogenesis is known to regulate tumor growth and metastasis by providing nutrients for tumor cells [3]. HCC is a typical angio-rich tumor characterized by abnormal angiogenesis. In clinical practice, multi-target tyrosine kinase inhibitors targeting vascular endothelial growth factor (VEGF) could inhibit the growth and development of $\mathrm{HCC}$ by suppressing angiogenesis. However, these drugs still have limitations [4-6]. Therefore, it is vital to explore new targets for the treatment of $\mathrm{HCC}$ by regulating HCC angiogenesis.

$\mathrm{NF}-\mathrm{\kappa B}$ pathway is a highly conserved signaling pathway, and its abnormal activation plays an important role in tumor occurrence and development. It is known that NF- $\mathrm{kB}$ has a wide range of transcriptional activities and multiple links to angiogenesis $[7,8]$. It has been proved that inhibition of NF- $\mathrm{KB}$ could eliminate the production of VEGF and then induce the suppression of angiogenesis in a variety of types of cancer [9]. Studies have indicated that NF- $\mathrm{kB}$ contributes to angiogenesis in prostate [10], breast [11], colorectal [12], and pancreatic cancers [13]. Inhibition of meiotic recombination protein (REC8) has been shown to promote NF-kB/p65 activity and its downstream gene VEGF, leading to tumor angiogenesis in the gastric cancer [14]. The expression of prenyl diphosphate synthase subunit 2 (PDSS2-DEL2) was found to be positively related to activation of the NF- $\mathrm{KB}$ pathway, leading to the metastasis and angiogenesis of HCC [15]. Therefore, inhibiting NF- $\kappa B$ activity, leading to decreased tumor-induced blood vessel formation, might be an important strategy for the treatment of HCC.

MicroRNAs (miRNAs) are endogenous noncoding RNAs, that are approximately 22 nucleotides in length, and are known to regulate various biological processes, including angiogenesis and tumor progression [16, 17]. miRNA-378a, including miR-378a-3p and miR$378 \mathrm{a}-5 \mathrm{p}$, is located on human chromosome $5 \mathrm{q} 32$ and has abundant biological functions [18]. The expression of miR-378a is involved in the regulation of mitochondria, glucose metabolism, autophagy, and other metabolic pathways $[19,20]$. In addition, miR-378a plays an active role in the occurrence and development of malignant tumor $[21,22]$. miR-378a-5p suppresses angiogenesis in oral squamous cell carcinoma by regulating of Kallikrein-related peptidase 4 (KLK4). miR-378a-3p could bind to the target genes, mitogen-activated protein kinase 1 (MAPK1) and growth factor receptor bound protein 2 (GRB2), leading to the silencing of their expression and reversing the cisplatin resistance of ovarian cancer cells [23]. The overexpression of miR378 also promotes the migration and invasion of human hepatoblastoma cells [24]. Pogribny et al. fed rats with the oncogenic agent tamoxifen to induce HCC. After 12 weeks and 24 weeks, the miRNA expression profiles were studied in the livers of rats, and it was found that miR-378 expression was decreased in the tamoxifentreated group versus the control group [25]. However, the mechanism by which miR-378a affects the occurrence and development of HCC is still unclear.

In this study, we identified a novel function of miR378a-3p: it plays an antitumor role in HCC angiogenesis, and high miR-378a-3p expression is correlated with a favorable prognosis. Further in vitro and in vivo experiments demonstrated that miR-378a-3p abolished the oncogenic function of NF-kB/p65 to silence its targeted gene TNF receptor associated factor 1 (TRAF1), an activator of NF-kB pathway. Moreover, p65 promoted the transcriptional expression of DNA methyltransferase 1 (DNMT1), which could promote miR-378a-3p promoter methylation. Overall, the regulatory network of $\mathrm{HCC}$ angiogenesis forms a positive feedback loop via DNMT1/miR-378a-3p/TRAF1/ $\mathrm{NF}-\mathrm{KB}$.

\section{Materials and methods Clinical samples}

A total of 108 pairs of primary HCC tissues and paracarcinoma tissues were obtained from patients undergoing surgery at the affiliated hospital of Nantong University between 2004 and 2010. Another cohort of 10 matched fresh HCC samples were collected from the same hospital. None of the patients had received chemotherapy, radiotherapy, or immunotherapy before undergoing surgery. The follow-up was completed in August 2015 (median follow-up 65 months; range, 2-95 months). The samples were collected promptly during surgical resection and stored at $-80^{\circ} \mathrm{C}$. The experimental protocol was approved by the ethics committee of the Affiliated Hospital of Nantong University. Additionally, written informed consent was obtained from all participants.

\section{Cell lines and culture condition}

The MHCC-97H, MHCC-97L and HCCLM3 cell lines were donated by the Liver Cancer Institute, ZhongShan Hospital. LO2, SMMC-7721 and human umbilical vein endothelial cells (HUVECs) were procured from GeneChem (Shanghai, China). All cell lines were cultured in Dulbecco's Modified Eagle's Medium (DMEM, Invitrogen, USA), supplemented with $10 \%$ fetal bovine serum (FBS, Clark Bioscience, USA), ampicillin (Gibco, USA), and streptomycin (Gibco, USA) in a $5 \% \mathrm{CO}_{2}$ humidified chamber at $37^{\circ} \mathrm{C}$. 


\section{Cell transfection and drug treatment}

The sequences of the mimic or inhibitors were designed and composed by GenePharma (Suzhou, China). The miR-378a-3p agomir and agomir-NC were synthesized and purified by GenePharma (Suzhou, China). Cell transfection was performed on a six-well plate using Lipofectamine 3000 reagent (Invitrogen, USA). Cells were collected $48 \mathrm{~h}$ post-transfection to detect the mRNA expression. DNMT1 siRNA, DNMT3A siRNA, DNMT3B siRNA, and TRAF1 siRNA were obtained from GenePharma (Suzhou, China). TRAF1, p65 and DNMT1 overexpression plasmid were obtained from GeneChem (Shanghai, China). The siRNA sequences are shown in Table S1 $[26,27]$. For drug treatment, cells were treated with $10 \mu \mathrm{M}$ 5-azacytidine (5-Aza, MedChemExpress, Shanghai, China) for $48 \mathrm{~h}, 50 \mu \mathrm{g} / \mathrm{ml}$ SN50 (MedChemExpress, New Jersey, USA) for $24 \mathrm{~h}$, or $60 \mu \mathrm{g} /$ $\mathrm{ml}$ lipopolysaccharide (LPS, Solarbio, Beijing, China) for $24 \mathrm{~h}$. All experiments were performed in triplicate.

\section{qRT-PCR analysis and fluorescence in situ hybridization (FISH) assay}

Total RNA was extracted with TRIzol reagent (Invitrogen, USA). qRT-PCR was performed following a previously described method [28]. The bulge-loop RT primer and qPCR primers specific for hsa-miR-378a-3p and hsa-miR378a-5p were designed and synthesized by RiboBio (Guangzhou, China). Table S2 lists the primers used in this study. A miR-378a-3p FISH kit was purchased from GenePharma (Suzhou, China) and the experiment was performed according to the manufacturer's instructions [29]. The results were analyzed by an IX71 inverted microscope (Olympus, Japan). All experiments were performed in triplicate.

\section{Subcellular fractionation and western blot assay}

Subcellular fractionation was performed with a Nuclear and Cytoplasmic Protein Extraction Kit (Sangon, Shanghai, China), in accordance with the manufacturer's instructions. Total protein separation and western blotting were performed as described previously [30]. The following antibodies were used: anti-p-ІкB $\alpha$ (Cell Signaling Technology, USA), anti-p-IKK $\beta$ (Abcam, Cambridge, MA, USA), anti- $\beta$-actin, anti-Lamin B1, anti-TRAF1 and anti-NF-kB p65 (Proteintech, Wuhan, China). All experiments were performed in triplicate.

\section{Immunohistochemistry (IHC)}

IHC was performed following a previously described method [30]. The following antibodies were used: antiCD34, anti-VEGF, anti-DNMT1, anti-TRAF1, and antiNF-kB p65 (Proteintech, Wuhan, China). Staining intensity was scored manually by two independent experienced pathologists as follows: $0=$ no staining, $1=$ weak staining, $2=$ moderate staining, and $3=$ strong staining. The percentage of positive cells was also assessed according to four scores: 1 (0-10\%), 2 (11-50\%), 3 (51-80\%), and 4 (81$100 \%)$. The final IHC score was calculated by multiplying the intensity score by the percentage of positive cells. CD34 antibody was used to stain vascular endothelial cells, and then the microvessel density (MVD) was calculated. The field of maximal CD34 expression was found in tumor tissues. Within this field, the area of maximal angiogenesis was selected, and microvessels were counted at $200 \times$ magnification. Low MVD was indicated by scores from 0 to 3 . High MVD was indicated by scores $\geq 4$ [31].

\section{Immunofluorescence assays}

Immunofluorescence assays were performed as described in our previous study [30]. Treated HCC cells were washed three times with cold phosphate-buffered saline (PBS, Gibco, USA), fixed with $4 \%$ paraformaldehyde (Beyotime, Shanghai, China) for $20 \mathrm{~min}$, treated with $0.1 \%$ of Triton X-100 (Beyotime, Shanghai, China) for $5 \mathrm{~min}$ and blocked in 5\% Bovine Serum Albumin (Solarbio, Beijing, China). Then cells were incubated overnight with anti-NF-kB p65 (Proteintech, Wuhan, China) at $4{ }^{\circ} \mathrm{C}$, followed by washing three times with PBS. Next, the cells were incubated with fluorescent Alexa Fluor 594-conjugated goat anti-rabbit IgG (ABclonal, Wuhan, China). Finally, the nuclei were labelled with DAPI (Cell Signaling Technology, USA) for $15 \mathrm{~min}$, and the images of stained cells were captured by the BX41 microscope (Olympus, Japan). All experiments were performed in triplicate.

\section{Wound healing, cell invasion and colony formation assay} We added 0.4- $\mu$ m-thick pore inserts (Corning, USA) to 6-well culture plates. HUVECs $\left(1 \times 10^{6}\right.$ cells $)$ were placed in the lower chambers and treated HCCLM3 and SMMC-7721 cells were placed in the upper chambers and co-cultured in DMEM with 5\% FBS for $48 \mathrm{~h}$. Next, we collected the treated HUVECs for wound healing assays, cell invasion assays, and colony formation assays. These experiments were performed as described previously [32]. All experiments were performed in triplicate.

\section{Tube formation assay}

We added Matrigel $(170 \mu \mathrm{L}, \mathrm{BD}$ Biosciences, USA) to cold 48-well culture plates and allowed it to solidify at $37^{\circ} \mathrm{C}$ for $30 \mathrm{~min}$. Next, treated HUVECs $\left(1 \times 10^{4}\right.$ cells/ well) were seeded onto the Matrigel layer. After incubation for $8 \mathrm{~h}$ at $37^{\circ} \mathrm{C}$, the formation of polygonal tubes was assessed microscopically at $100 x$ magnification. All experiments were performed in triplicate. 


\section{Experiments with animals}

Male BALB/C nude mice aged 6 weeks were purchased from the Animal Laboratory Center of Nantong University (Nantong, China). The matrix plug assay was used to assess angiogenic capacity. HCCLM3 and SMMC-7721 cells were treated with miR-378a-3p mimic or inhibitors for $48 \mathrm{~h}$. After that, the cells were resuspended in a mixture of serum-free medium and Matrigel (BD Biosciences, USA) at a density of $5 \times 10^{6}$ cells $/ 450 \mu \mathrm{L}$ and subcutaneously injected into nude mice ( 5 mice for each group). The nude mice were euthanized 7 days later, and the matrix plug was removed for further analysis. The subcutaneous xenograft mouse model was used to assess the tumor growth rate. HCCLM3 cells $\left(5 \times 10^{6}\right)$ transfected with miR-378a-3p agomir or agomir-NC for $48 \mathrm{~h}$, were subcutaneously injected into the upper part of the forelimb (5 mice per group). Tumor volume was measured every three days and calculated as $\mathrm{V}=0.5 \times$ length $\times$ width $^{2}$. The nude mice were sacrificed after 24 days, and the tumor tissues were extracted and collected for subsequent studies [33]. All animal experiments were approved by the Institutional Animal Care and Use Committee of Nantong University following the current guidelines for animal care and welfare.

\section{Elisa}

HCC cells were seeded in 6-well plates and incubated in serum-free medium for $24 \mathrm{~h}$. The conditioned medium was collected, and the concentration of VEGF was quantified using VEGF ELISA kits (Jianglai Bio, Shanghai, China) according to the manufacturer's instructions. All experiments were performed in triplicate.

\section{Luciferase reporter assays}

NF- $\kappa B$ luciferase assays were performed via the cotransfection with the NF-kB-luciferase plasmid, control luciferase plasmid, pRL-TK Renilla, miRNA mimic and miRNA mimic control into HCC cells by Lipofectamine 3000. The $3^{\prime}$ - untranslated region (UTR) sequences of TRAF1 containing miR-378a-3p binding sites were synthesized and cloned into the luciferase reporter vector. Next, SMMC-7721 and HCCLM3 cells transfected with miRNA mimic and control were co-transfected with luciferase reporter vectors. The wild-type DNMT1 promoter and a promoter with mutated NF- $\mathrm{kB}$-binding sites were designed by GeneChem. DNMT1-WT or DNMT1-MUT was co-transfected with pcDNA3.1 vector or pcDNA3.1 p65. After $48 \mathrm{~h}$, the luciferase activity was measured with a dual-luciferase assay kit (Beyotime, Shanghai, China). The results are presented as the relative luciferase activity of Renilla, which was normalized to the activity of firefly luciferase. All the luciferase reporter assays plasmids were purchased from GeneChem
(Shanghai, China). All experiments were performed in triplicate.

\section{Chromatin immunoprecipitation (ChIP)}

ChIP was performed using a previously described method [34]. ChIP assays were performed with a Pierce Magnetic ChIP Kit (Thermo Fisher Scientific, USA) according to the manufacturer's protocol. Anti-p65 antibody and normal IgG (Multiscience, Hangzhou, China) were used for immunoprecipitation. The primer sequences for the ChIP assays were shown in Table S2. All experiments were performed in triplicate.

\section{Online bioinformatics analysis}

GSE54751, GSE108724 and GSE174608 were downloaded from the Gene Expression Omnibus (GEO) database to assess the differential miR-378a-3p expression. The Cancer Genome Atlas (TCGA) database was used to analyse the expression correlation between miR-378a-3p and DNMT1, TRAF1 or VEGFA, miR-378a expression, and the prognostic significance of DNMT1 and VEGFA. Putative miR-378a-3p target genes were predicted by miRWalk (http://mirwalk.umm.uni-heidelberg.de/) and miRTarBase (http://mirtarbase.mbc.nctu.edu.tw/). The Gene Expression Profiling Interactive Analysis (GEPIA) database (http://gepia2.cancer-pku.cn/) was used to analyse the expression correlation between DNMT1 and p65. JASPAR (jaspar.genereg.net/) was used to predict the putative transcription factors of DNMT1. The Search Tool for the Retrieval of Interacting Genes/Proteins (STRING) dataset (https://string-db.org/) was used to predict the functional pathways correlated with TRAF1. SurvExpress data (http://bioinformatica.mty.itesm.mx: 8080/Biomatec/SurvivaX.jsp) was used to predict the prognostic significance of TRAF1.

\section{RNA sequencing (RNA-seq)}

Three repeated pairs of SMMC-7721/miR-378a-3p mimic and control groups were prepared for RNA-seq, which was performed by GENEWIZ (Soochow, Suzhou, China). Significant differences in mRNA expression ( $P$-value $<0.05$ and $|\log 2 \mathrm{FC}|>1)$ between groups were identified using the fold change cut-off.

\section{Statistical analysis}

The measured data are presented as the mean \pm SD. Student's t-test was used for statistical comparisons between experimental groups. The correlations between miR378a-3p expression and various clinicopathological factors were performed using the chi-squared test. The Cox regression model was used to evaluate prognostic factors. Logistic regression analysis was performed to identify risk factors affecting miR-378a-3p levels in HCC. The 
probability of differences in overall survival (OS) and disease-free survival (DFS) were assessed with KaplanMeier and log-rank tests. Spearman's correlation rank analysis was used to analyze categorical variables. All statistical analyses were performed with SPSS v24.0 software. $P<0.05$ was considered to indicate a statistically significant difference.

\section{Results}

miR-378a-3p expression is downregulated in HCC patients and correlated with HCC angiogenesis

To elucidate the functional roles of miR-378a in HCC, we found that miR-378a levels were downregulated in HCC tissues compared to normal tissues from the TCGA and GSE54751 datasets (Fig. 1A, B). Next, we compared the mRNA levels of the two strands of miR-378a, miR378a-3p and miR-378a-5p, in 10 matched fresh HCC and corresponding normal tissues. miR-378a-3p and miR378a-5p expression were significantly downregulated in HCC, and miR-378a-3p showed a substantially higher difference (Fig. 1C, D). Analysis of the GSE108724 and GSE174608 datasets and 108 matched samples also confirmed that miR-378a-3p was downregulated in HCC (Fig. 1E-G). We combined the clinical data of 108 patients with the data for the corresponding samples, and we found that the decreased miR-378a-3p expression was closely associated with thrombosis of tumor blood vessel and MVD (Table 1). Moreover, multivariate logistic regression analysis showed that the expression of miR-378a-3p was significantly inversely correlated with MVD $(p<0.001$, odds ratio $[\mathrm{OR}]=0.070,95 \%$ confidence interval $[\mathrm{CI}]$ : $0.027-0.179)$. The results were also validated in 10 paired HCC and normal tissues via a FISH assay for assessing miR-378a-3p and IHC for assessing MVD (Fig. 1H, I). Kaplan-Meier analysis showed that HCC patients with low miR-378a-3p expression had worse OS and DFS rates than those with higher miR-378a-3p expression (Fig. 1J, $\mathrm{K})$. Additionally, the results of Cox multivariate regression analysis revealed that miR-378a-3p was an independent, effective prognostic factor (Table 2).

\section{miR-378a-3p inhibited HCC angiogenesis in vitro and in vivo}

To further study the function of miR-378a-3p in HCC angiogenesis. qRT-PCR was performed to investigate the expression of miR-378a-3p in four HCC cell lines and the human normal liver cell line LO2. The expression of miR-378a-3p in HCC cell lines was significantly lower than that in LO2 cells (Fig. 2A). Then, we established miR-378a-3p-overexpressing HCCLM3 and MHCC-97H cells and miR-378a-3p-knockdown
SMMC-7721 and MHCC-97 L cells (Fig. 2B, Fig. S1A). A co-culture system was used to culture the treated HCC cells along with HUVECs for $48 \mathrm{~h}$ (Fig. 2C). Reduced proliferation was observed in HUVECs cocultured with HCC cells with high miR-378a-3p expression (Fig. 2D, E, Fig. S1B-F). Wound healing assays and Transwell assays indicated that the migration and invasion ability of HUVECs was decreased after co-culture with the miR-378a-3p-overexpressing HCC cells, while miR-378a-3p knockdown increased migration and invasion (Fig. 2F, G, Fig. S1G-K). The supernatant from miR-378a-3p-overexpressing HCC cells inhibited HUVEC tube formation (Fig. 2H, Fig. S1L-M). The Matrigel plug assay was used to analyze the neovascularization potential to further identify the antitumor function of miR-378a-3p in HCC. The Matrigel plugs collected from the miR-NC group had more blood vessels (Fig. 2I). The IHC results showed that the MVD and the expression of VEGF were lower in the miR-378a-3poverexpression group than in the NC group (Fig. 2J, K). The ELISA results indicated that the secretion of VEGF was downregulated by the miR-378a-3p mimic and upregulated by the miR-378a-3p inhibitor in the conditioned medium of HCC cell lines (Fig. 2L, Fig. S1N). Thus, our data suggested that miR-378a-3p negatively regulated $\mathrm{HCC}$ angiogenesis in vitro and in vivo.

\section{TRAF1 acted as a direct target gene of miR-378a-3p in HCC cells}

RNA-seq was performed to understand the molecular mechanism of miR-378a-3p-induced inhibition of angiogenesis in SMMC-7721 cells. We identified 297 differentially expressed genes (DEGs), including 133 upregulated DEGs and 164 downregulated DEGs (Fig. 3A). Next, we used the online bioinformatics tools miRWalk and miRTarBase to predict the potential target of miR-378a-3p. Combined with these data, TRAF1 was seen as the only putative target of miR378a-3p for further research (Fig. 3B). According to the software prediction, we found that TRAF1 had a potential binding site of miR-378a-3p, and then we inserted wild-type or mutant TRAF1 into a luciferase reporter vector (Fig. 3C). Transfection of the miR378a-3p mimic significantly inhibited the luciferase activity of the wild-type (WT) TRAF1 reporter, and this effect was completely eradicated for the mutanttype (MUT) reporter (Fig. 3D). Additionally, the miR378a-3p mimic downregulated the mRNA and protein expression of TRAF1, while the miR-378a-3p inhibitor upregulated TRAF1 expression in HCC cells (Fig. 3E, F). Thus, these results indicated that TRAF1 acted as a direct target of miR-378a-3p in HCC. 


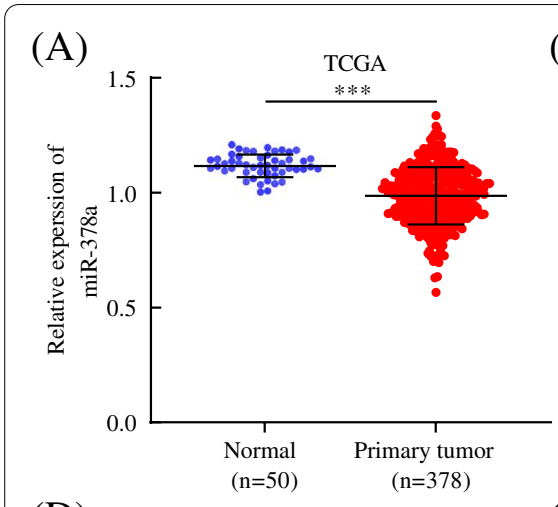

(D)

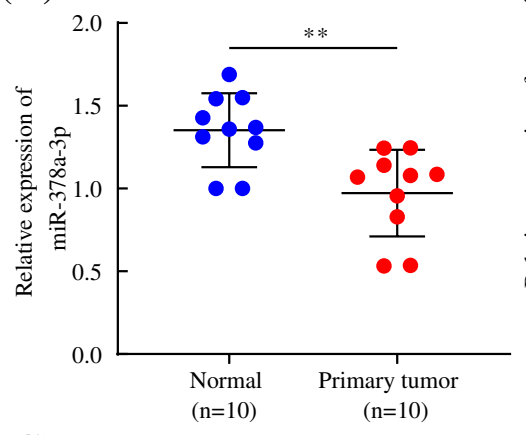

(G)

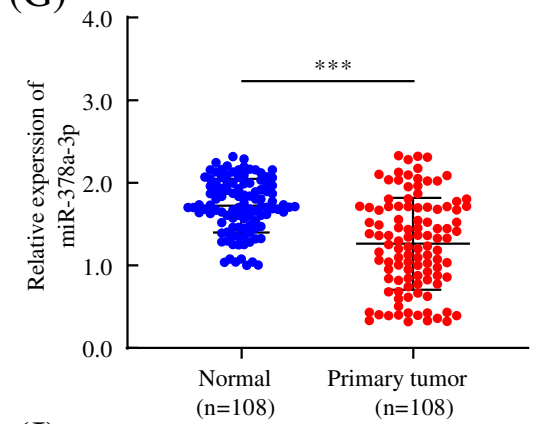

(J)

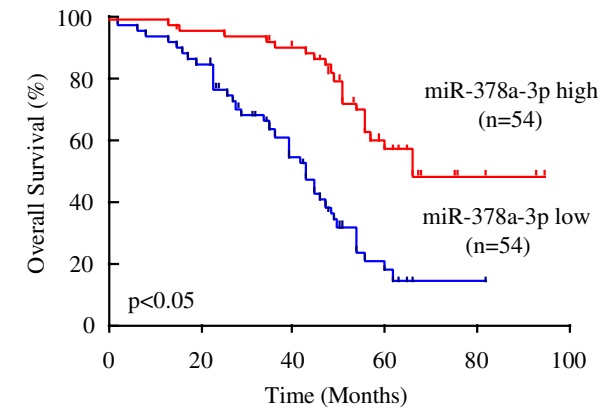

(B)

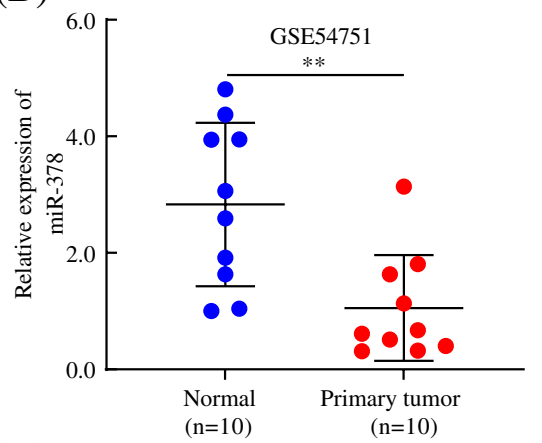

(E)

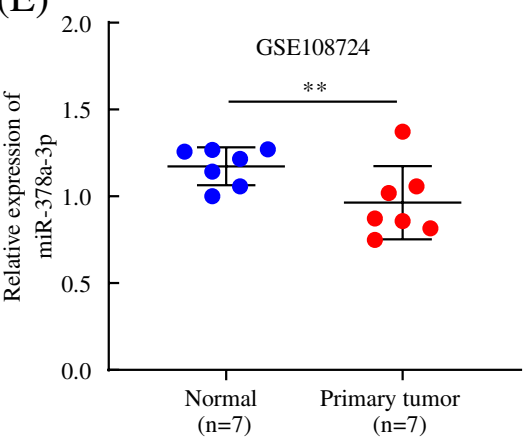

$(\mathrm{H})$

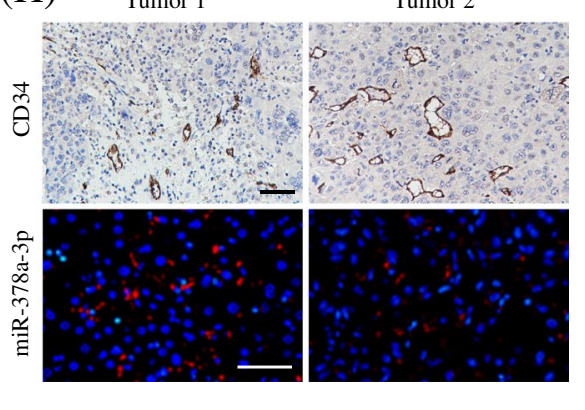

(K)

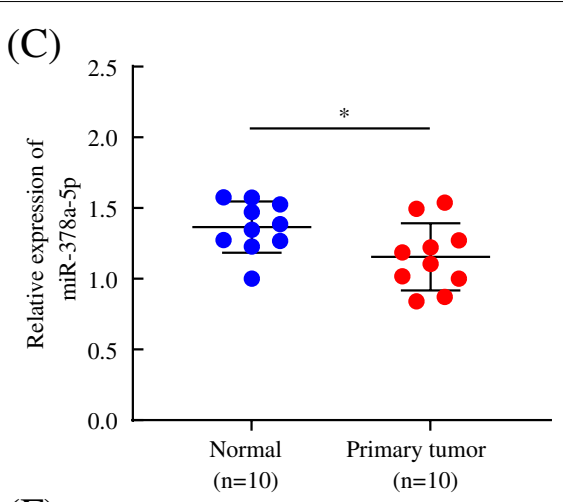

(F)

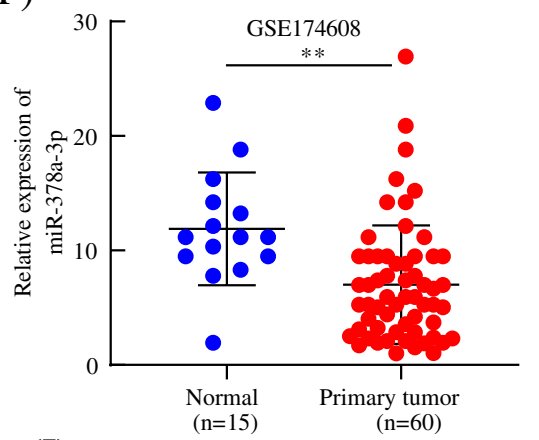

(I)

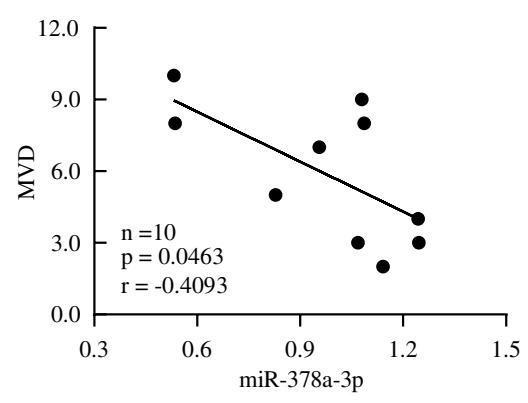

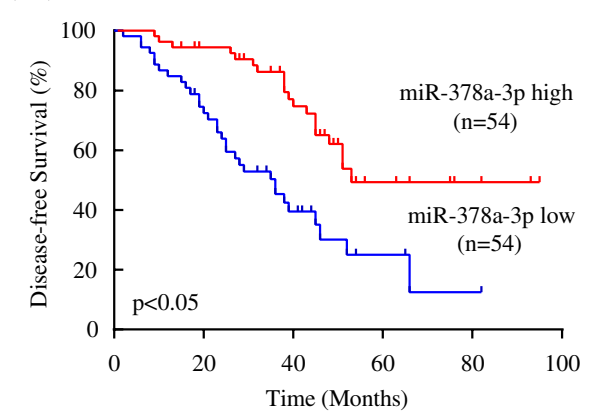

Fig. 1 miR-378a-3p expression is downregulated in HCC patients and correlated with HCC angiogenesis. A, B The mRNA expression of miR-378a in HCC and paired normal tissues was analyzed based on the TCGA and GEO databases. C, D Two chains of miR-378a were detected in 10 matched paired normal tissues and HCC tissues by qRT-PCR. E-G Relative miR-378a-3p mRNA expressions was measured in GEO datasets and in 108 pairs of specimens. H Tumor sections were stained with anti-CD34 for IHC assays and miR-378a-3p for FISH assays. IThe correlation line between miR-378a-3p and MVD was analyzed by linear regression analysis. J, K OS and DFS were analyzed in HCC patients with high or low expression of miR-378a-3p by the Kaplan-Meier method. ${ }^{*} P<0.05 ;{ }^{* *} P<0.01 ;{ }^{* *} P<0.001$ 
Table 1 Relationships between miR-378a-3p expression and clinicopathological characteristics of HCC patients

\begin{tabular}{|c|c|c|c|c|}
\hline Clinicopathological characteristics & $\mathbf{n}$ & Low expression & High expression & $P$ value \\
\hline Total & 108 & 54 & 54 & \\
\hline Gender & & & & 0.060 \\
\hline Male & 75 & 33 & 42 & \\
\hline Female & 33 & 21 & 12 & \\
\hline Age (years) & & & & 0.440 \\
\hline$\leq 60$ & 83 & 41 & 42 & \\
\hline$>60$ & 25 & 13 & 12 & \\
\hline Grade of differentiation & & & & 0.123 \\
\hline Low & 56 & 32 & 24 & \\
\hline High-Middle & 52 & 22 & 30 & \\
\hline Tumor diameter $(\mathrm{cm})$ & & & & 0.123 \\
\hline$\leq 5$ & 50 & 29 & 21 & \\
\hline$>5$ & 58 & 25 & 33 & \\
\hline Liver function (Child-Pugh stage) & & & & 0.588 \\
\hline A & 92 & 45 & 47 & \\
\hline $\mathrm{B}$ or $\mathrm{C}$ & 16 & 9 & 7 & \\
\hline Hepatocirrhosis & & & & 0.288 \\
\hline Absent & 31 & 13 & 18 & \\
\hline Present & 77 & 41 & 36 & \\
\hline HBV infection & & & & 0.555 \\
\hline Absent & 43 & 20 & 23 & \\
\hline Present & 65 & 34 & 31 & \\
\hline Thrombosis of tumor blood vessel & & & & 0.011 \\
\hline Absent & 65 & 26 & 39 & \\
\hline Present & 43 & 28 & 15 & \\
\hline $\operatorname{AFP}(n g / m l)$ & & & & 0.083 \\
\hline$\leq 20$ & 53 & 22 & 31 & \\
\hline$>20$ & 55 & 32 & 23 & \\
\hline BCLC stage & & & & 0.552 \\
\hline A & 41 & 19 & 22 & \\
\hline$B, C$, or D & 67 & 35 & 32 & \\
\hline Envelope & & & & 0.700 \\
\hline Absent & 52 & 25 & 27 & \\
\hline Present & 56 & 29 & 27 & \\
\hline Tumor satellite & & & & 0.079 \\
\hline Absent & 63 & 27 & 36 & \\
\hline Present & 45 & 27 & 18 & \\
\hline MVD & & & & $<0.001$ \\
\hline High & 59 & 45 & 14 & \\
\hline Low & 49 & 9 & 40 & \\
\hline
\end{tabular}

AFP serum alpha fetoprotein, $H B V$ hepatitis B virus, BCLC Barcelona Clinic Liver Cancer

miR-378a-3p inhibited HCC angiogenesis by targeting TRAF1 Rescue experiments were performed to further confirm whether silencing miR-378a-3p could facilitate HCC angiogenesis by upregulating TRAF1 expression. The analysis showed that, compared with transfection of miR-378a-3p mimic alone, simultaneous transfection of TRAF1overexpressing plasmid could reverse the decrease in angiogenesis and secreted VEGF levels in conditioned medium, while the cells transfected with miR-378a-3p inhibitor and TRAF1 siRNA exhibited significantly lower angiogenesis ability and levels of secreted VEGF than the cells transfected with miR-378a-3p inhibitor (Fig. 4A-K). These results suggested that TRAF1 could attenuate the inhibitory effect of miR-378a-3p on HCC cells. 
Table 2 Univariate and multivariable analyses of OS and DFS in HCC patients

\begin{tabular}{|c|c|c|c|c|c|c|}
\hline \multirow[t]{3}{*}{ Variable } & \multicolumn{3}{|l|}{ os } & \multicolumn{3}{|l|}{ DFS } \\
\hline & \multirow{2}{*}{$\begin{array}{l}\text { Univariate } \\
\text { analysis } \\
P>|z|\end{array}$} & \multicolumn{2}{|c|}{ Multivariable analysis } & \multirow{2}{*}{$\begin{array}{l}\text { Univariate } \\
\text { analysis } \\
P>|z|\end{array}$} & \multicolumn{2}{|c|}{ Multivariable analysis } \\
\hline & & $P>|z|$ & $\mathrm{HR}(95 \% \mathrm{Cl})$ & & $P>|z|$ & $\mathrm{HR}(95 \% \mathrm{Cl})$ \\
\hline \multicolumn{7}{|l|}{ miR-378a-3p expression } \\
\hline Low $(n=54)$ vs. high $(n=54)$ & $<0.001$ & 0.003 & $0.414(0.232-0.736)$ & 0.001 & 0.010 & $0.454(0.249-0.828)$ \\
\hline \multicolumn{7}{|l|}{ Gender } \\
\hline Male $(n=75)$ vs. female $(n=33)$ & 0.944 & & & 0.737 & & \\
\hline \multicolumn{7}{|l|}{ Age (years) } \\
\hline$\leq 60(n=83)$ vs. $>60(n=25)$ & 0.518 & & & 0.837 & & \\
\hline \multicolumn{7}{|l|}{ Grade of differentiation } \\
\hline Low $(n=56)$ vs. middle-high $(n=52)$ & 0.330 & & & 0.444 & & \\
\hline \multicolumn{7}{|l|}{ Tumor diameter $(\mathrm{cm})$} \\
\hline$\leq 5(n=50)$ vs. $>5(n=58)$ & 0.588 & & & 0.294 & & \\
\hline \multicolumn{7}{|l|}{ Liver function (Child-Pugh stage) } \\
\hline $\mathrm{A}(n=92)$ vs. $\mathrm{B}$ or $\mathrm{C}(n=16)$ & 0.901 & & & 0.980 & & \\
\hline \multicolumn{7}{|l|}{ Hepatocirrhosis } \\
\hline Absent $(n=31)$ vs. present $(n=77)$ & 0.874 & & & 0.698 & & \\
\hline \multicolumn{7}{|l|}{ Hepatitis B virus } \\
\hline Absent $(n=43)$ vs. present $(n=65)$ & 0.189 & & & 0.692 & & \\
\hline \multicolumn{7}{|l|}{ Tumor thrombus } \\
\hline Absent $(n=65)$ vs. present $(n=43)$ & 0.079 & & & 0.052 & & \\
\hline \multicolumn{7}{|l|}{$\operatorname{AFP}(\mathrm{ng} / \mathrm{ml})$} \\
\hline$\leq 20(n=53)$ vs. $>20(n=55)$ & 0.264 & & & 0.973 & & \\
\hline \multicolumn{7}{|l|}{ BCLC stage } \\
\hline I $(n=41)$ vs. II, III, or IV $(n=67)$ & 0.194 & & & 0.149 & & \\
\hline \multicolumn{7}{|l|}{ Envelope } \\
\hline Absent $(n=52)$ vs. present $(n=56)$ & 0.142 & & & 0.946 & & \\
\hline \multicolumn{7}{|l|}{ Tumor satellite } \\
\hline Absent $(n=63)$ vs. present $(n=45)$ & 0.146 & & & 0.411 & & \\
\hline \multicolumn{7}{|l|}{ MVD } \\
\hline High $(n=59)$ vs. Low $(n=49)$ & $<0.001$ & 0.018 & 2.048(1.129-3.715) & 0.001 & 0.022 & $2.036(1.106-3.746)$ \\
\hline
\end{tabular}

\section{miR-378a-3p inhibited the activation of NF- $\mathrm{kB}$ signaling pathway by downregulating TRAF1 expression}

To identify the molecular mechanism by which miR378a-3p inhibits HCC angiogenesis. The STRING dataset was used to predict the top 10 functional pathways correlated with TRAF1 (Fig. 5A). As others have shown that, TRAF1 could activate the NF- $\mathrm{B}$ signaling pathway and promotes cancer development [35]. Therefore, we performed luciferase reporter assays to determine the function of miR-378a-3p in NF- $\mathrm{kB}$ signaling activation and found that the relative luciferase activity of $\mathrm{NF}-\mathrm{\kappa B}$ was reduced in miR-378a-3p-overexpressing

(See figure on next page.)

Fig. 2 miR-378a-3p expression inhibited HCC angiogenesis in vitro and in vivo. A qRT-PCR was used to analyze the mRNA expression of miR-378a-3p in different HCC cell lines. B HCCLM3 and SMMC-7721 cells were transfected with miR-378a-3p mimic, mimic-NC, inhibitor, or inhibitor-NC and analyzed by qRT-PCR. C A working model of co-culture. D, E Treated HUVECs were evaluated by the CCK-8 and colony formation assays to analyze cell viability. F, G Wound healing assay and invasion assay were performed, and the numbers of migrating, or invading cells/ field were recorded. $\mathbf{H}$ miR-378a-3p mimic, mimic-NC, inhibitor, or inhibitor-NC RNA was transfected into HCCLM3 and SMMC-7721 cells for 48 h, and then tube formation assays were performed for HUVECs co-cultured with conditioned medium collected from HCC cells. I Matrigel plugs with treated HCC cells were used to assess angiogenesis potential. $\mathbf{J}, \mathbf{K}$ Matrigel plugs were collected to perform IHC analysis using anti-CD34 and anti-VEGF antibodies. L The VEGF protein concentration in the conditioned medium of treated HCC cells was detected by ELISA. * $P<0.05$; ${ }^{*} P<0.01$; ${ }^{* * *} P<0.001$ 
(A)
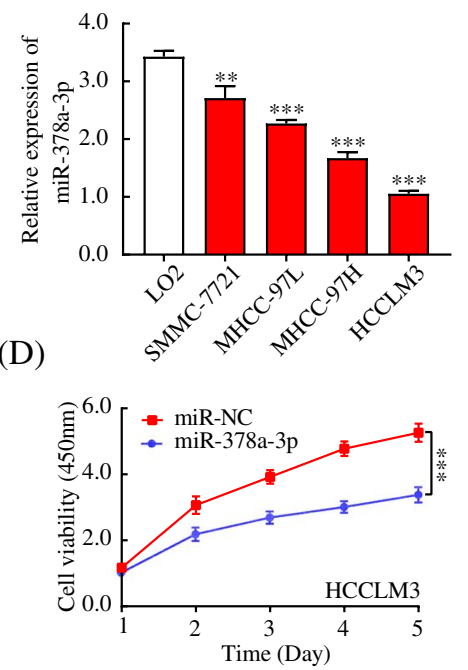

(G)

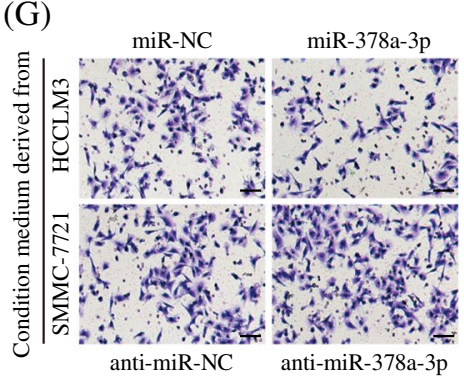

(I)

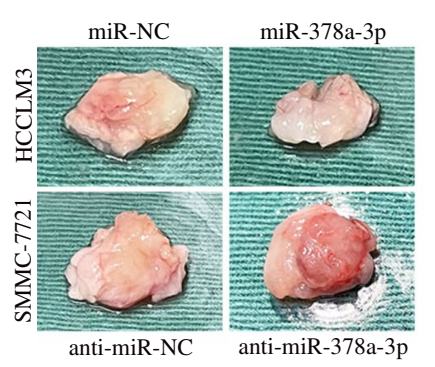

(K)

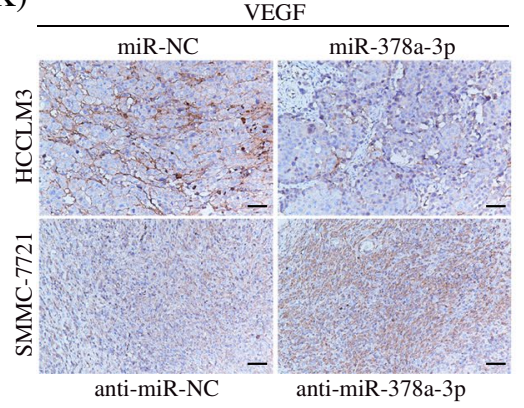

(J)
(B)
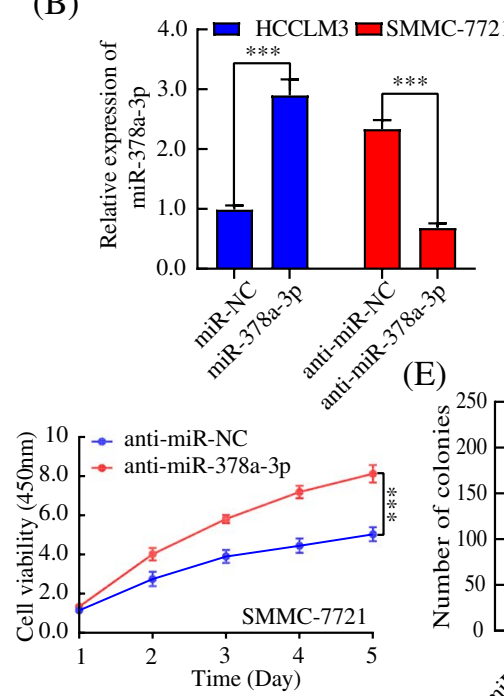

(E) HCCLM3 $_{\text {SMMC-7721 }}$
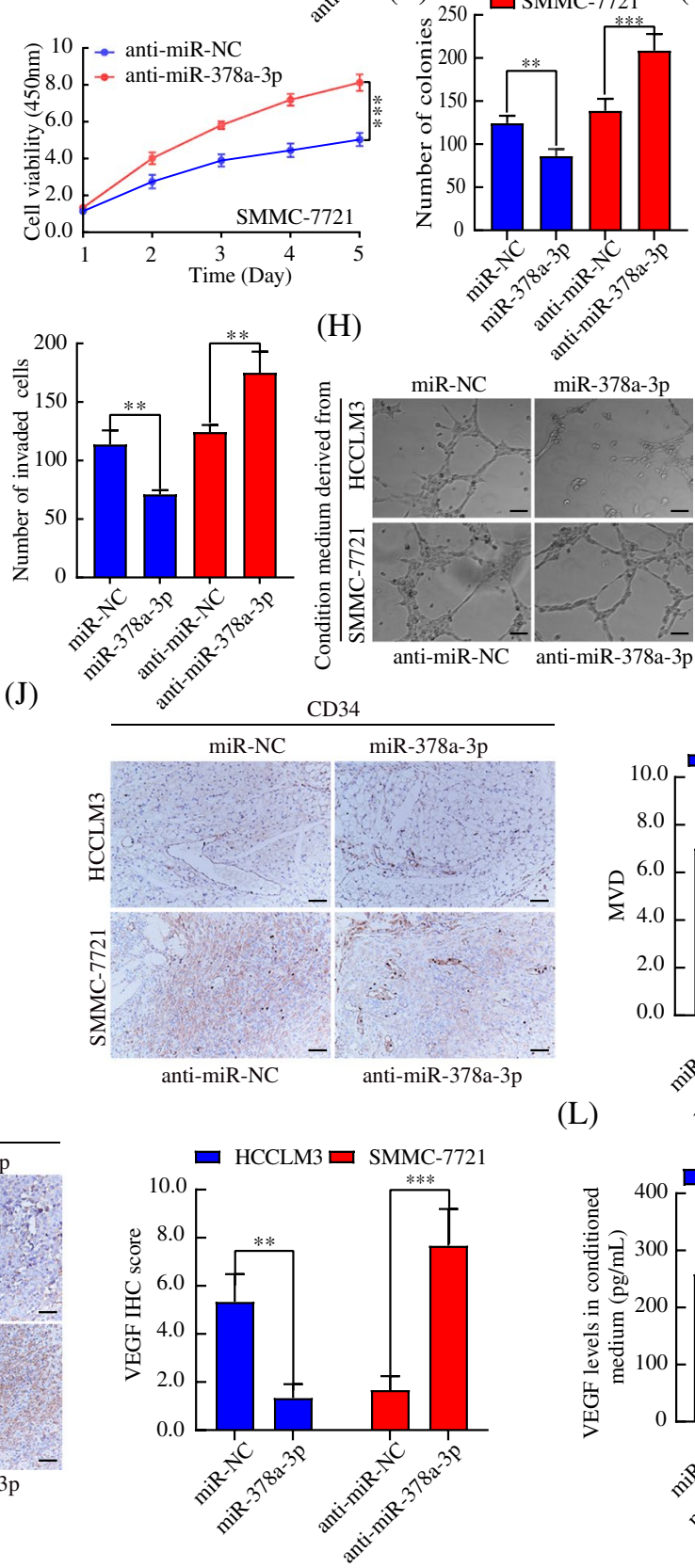

(C)

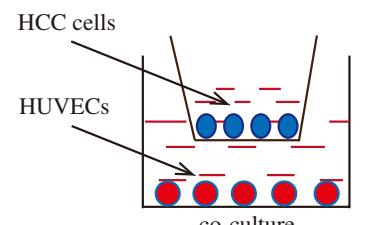

(F) 100 PCCLM3
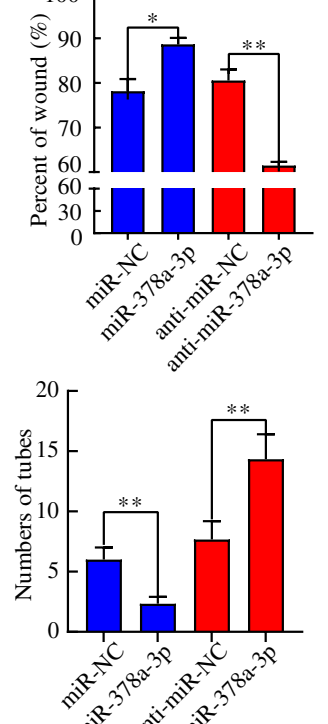

HCCLM3

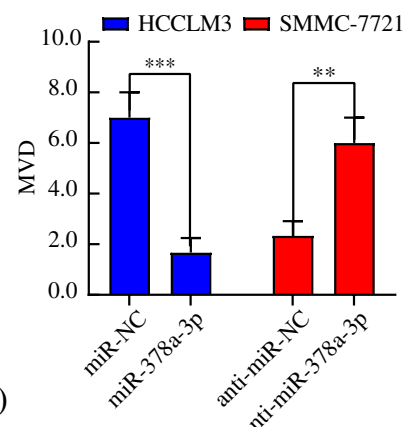

(L)

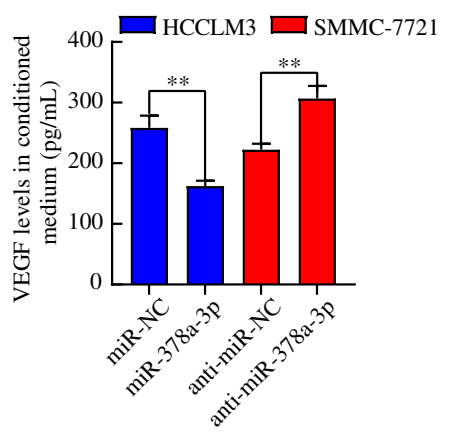

Fig. 2 (See legend on previous page.) 


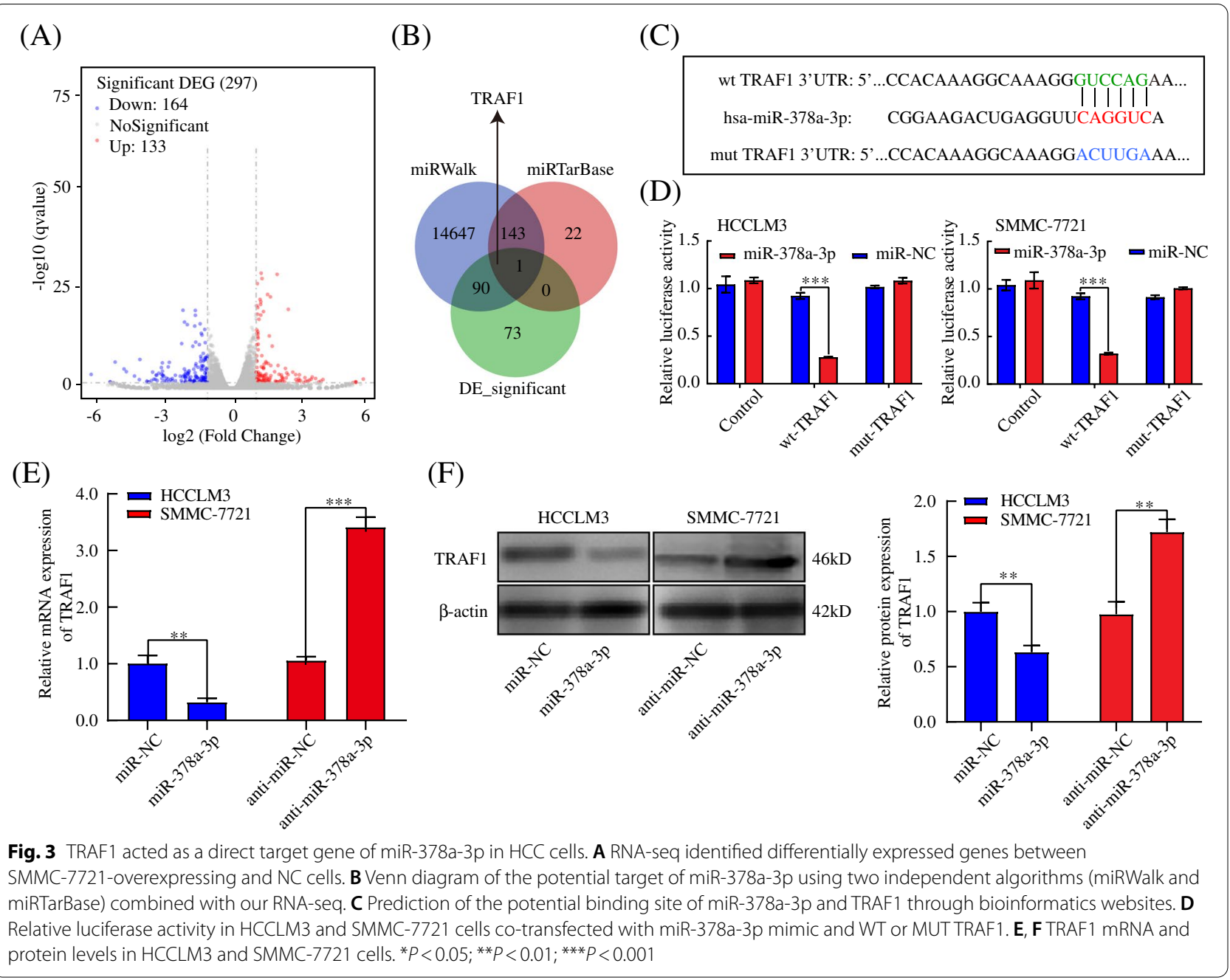

cells and was increased in miR-378a-3p knockdown cells (Fig. 5B, C). Moreover, the results of immunofluorescence assays showed that the nuclear translocation of p65 was decreased in miR-378a-3p-overexpressing cells but increased in miR-378a-3p knockdown cells (Fig. 5D, E). The western blot results showed that the overexpression of miR-378a-3p inhibited the phosphorylation of IKB $\alpha$ and IKK $\beta$ while miR-378a-3p knockdown increased their phosphorylation. Additionally, the upregulated expression of miR-378a-3p reduced nuclear p65 expression, whereas knockdown of miR378a-3p increased nuclear p65 expression (Fig. 5F, G). To further characterize that NF- $\mathrm{KB}$ activation involved miR-378a-3p-mediated in HCC angiogenesis, we compared the cells transfected with miR-378a-3p NC, mimic, and mimic combined with LPS, the activator of NF- $\kappa B$ pathway, LPS reversed the proliferation, migration, invasion and angiogenesis abilities inhibitions of miR-378a-3p and the results were also confirmed by the transfection of miR-378a-3p inhibitor and SN50, the inhibitor of NF-kB pathway (Fig. S2A-J). ELISA also demonstrated that the secretion of VEGF in conditioned medium of HCC cell lines was upregulated by miR-378a-3p mimic and LPS compared with miR378a-3p mimic alone, while the cells transfected with miR-378a-3p inhibitor and treated with SN50 exhibited lower secretion of VEGF (Fig. S2K). Moreover, western blot analysis confirmed that LPS attenuated the inhibitory effect of the miR-378a-3p mimic and that SN50 repressed the promoting effect of the miR-378a-3p inhibitor (Fig. S3A, B). Taken together, our data suggested that miR-378a-3p inhibited HCC angiogenesis by suppressing the activation of the NF- $\mathrm{kB}$ signaling pathway.

\section{miR-378a-3p is hypermethylated by DNMT1 and silenced in HCC tissues and cells}

Methylation of promoter DNA can reduce miRNA expression [36, 37]. We treated HCCLM3 and SMMC7721 cells with a demethylating agent, 5 -aza-CdR, to 


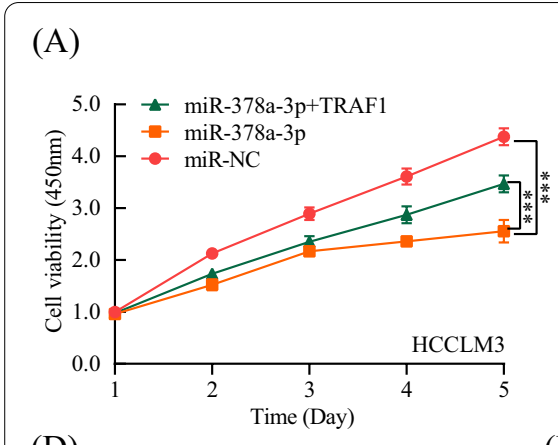

(D)

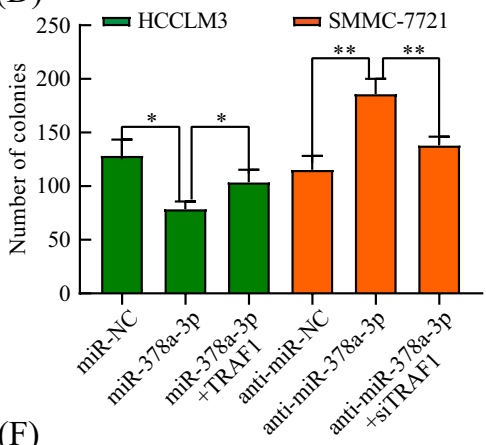

(F)

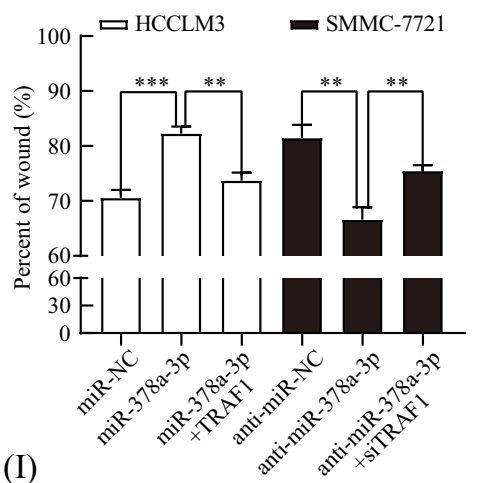

(I)

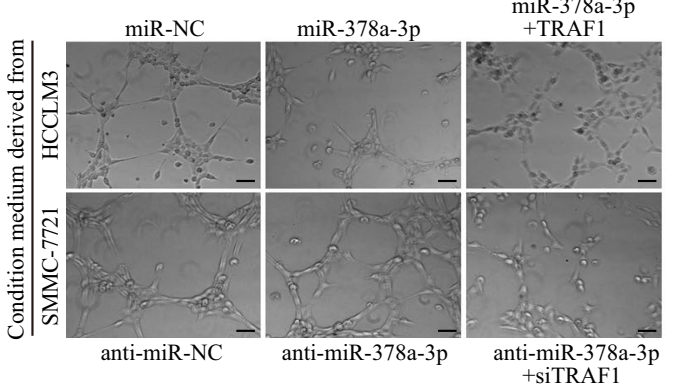

(B)

(E)

(G)

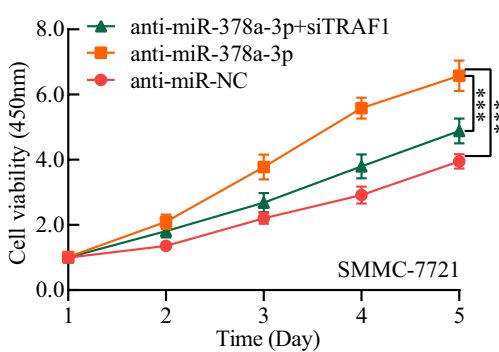

Condition medium derived from HCCLM3
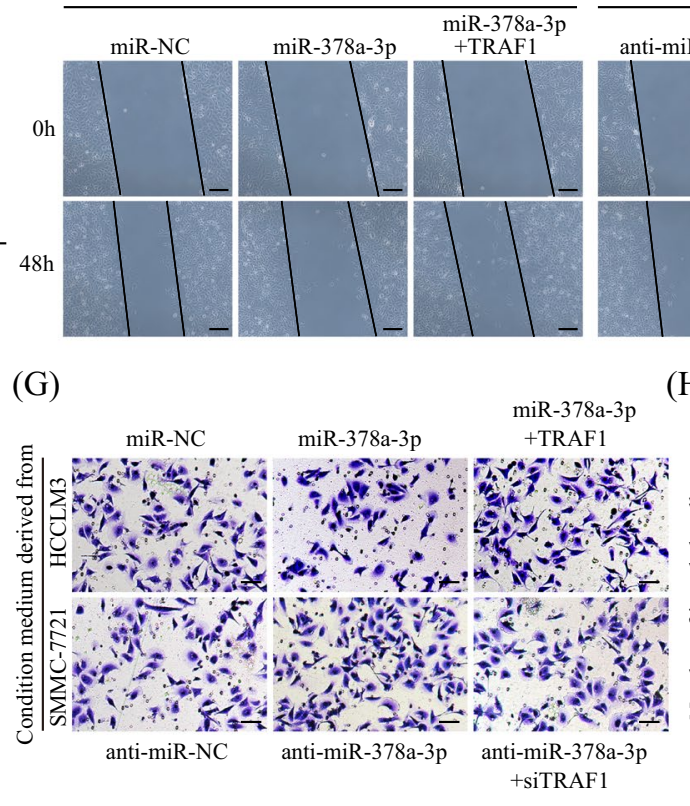

(J)

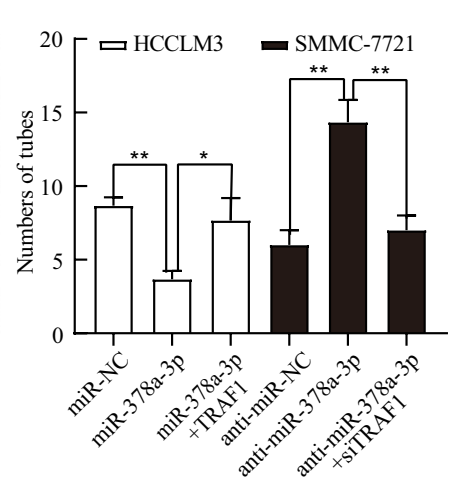

(C)

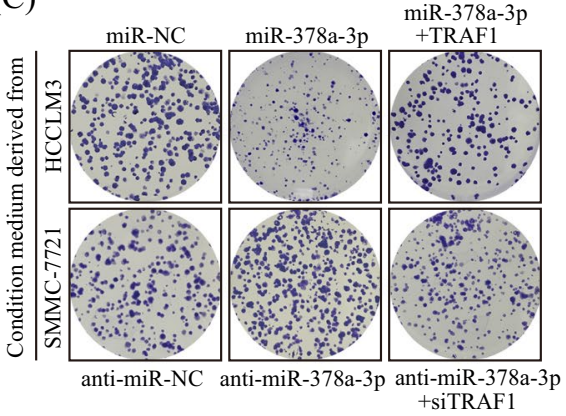

Condition medium derived from SMMC-7721

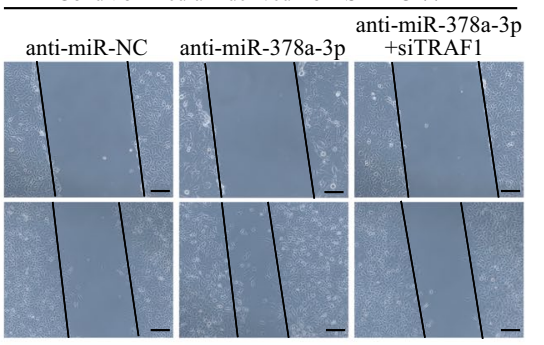

(H)
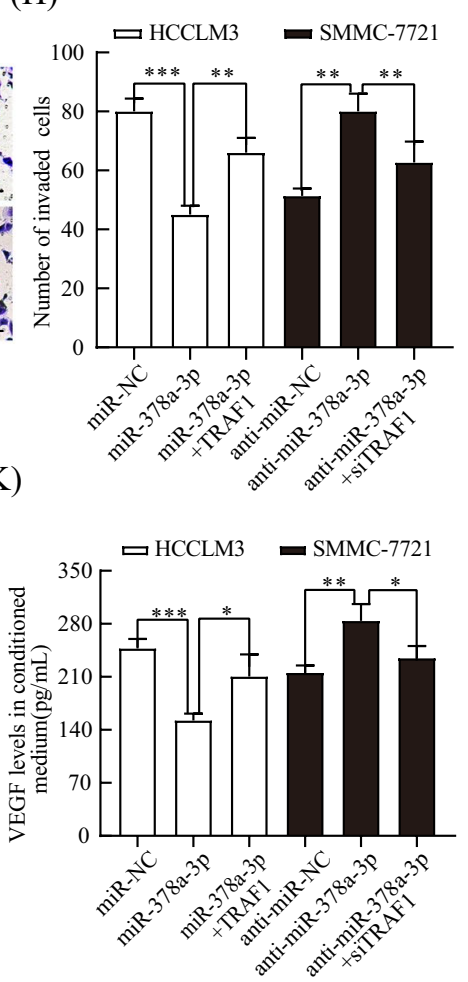

Fig. 4 miR-378a-3p inhibited HCC angiogenesis by targeting TRAF1. A-D Cell viability of HCCLM3 and SMMC-7721 cells transfected with mimic NC, miR-378a-3p, or miR-378a-3p plus TRAF1 and anti-miR-NC, anti-miR-378a-3p, or anti-miR-378a-3p plus siTRAF1 detected by CCK-8 and colony formation assays. E-J Migration, invasion and angiogenesis of HCCLM3 and SMMC-7721 cells transfected with mimic NC, miR-378a-3p, or miR-378a-3p plus TRAF1 and anti-miR-NC, anti-miR-378a-3p, or anti-miR-378a-3p plus siTRAF1 detected by wound healing, invasion and tube formation assays. KVEGF protein concentration in the condition medium of HCCLM3 and SMMC-7721 cells transfected with mimic NC, miR-378a-3p, or miR-378a-3p plus TRAF1 and anti-miR-NC, anti-miR-378a-3p, or anti-miR-378a-3p plus siTRAF1, as detected by ELISA. * $P<0.05$; ${ }^{* *} P<0.01 ;{ }^{* * *} P<0.001$ 


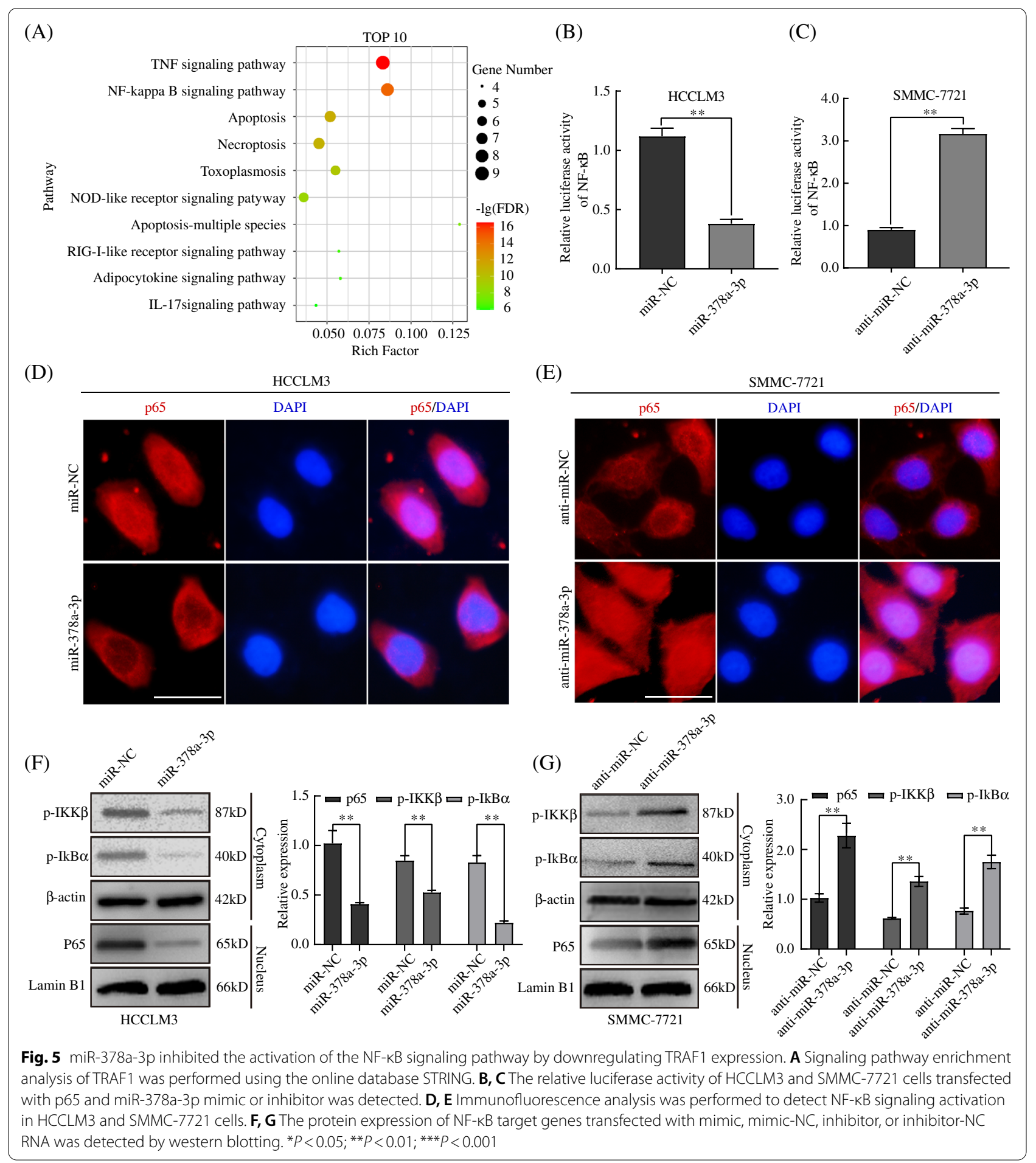

confirm whether the decrease in miR-378a-3p in HCC was caused by DNA methylation. As expected, the expression of miR-378a-3p was dramatically increased after treatment with 5-Aza-CdR (Fig. 6A, B). Because the miR-378a-3p promoter is hypermethylated in
HCC, we hypothesized that the deregulation of a specific methylase or demethylase induces this process. To clarify the potential roles of the various DNMTs in mediating miR-378a-3p promoter methylation in HCC, we knocked down DNMT1, DNA methyltransferase 3 


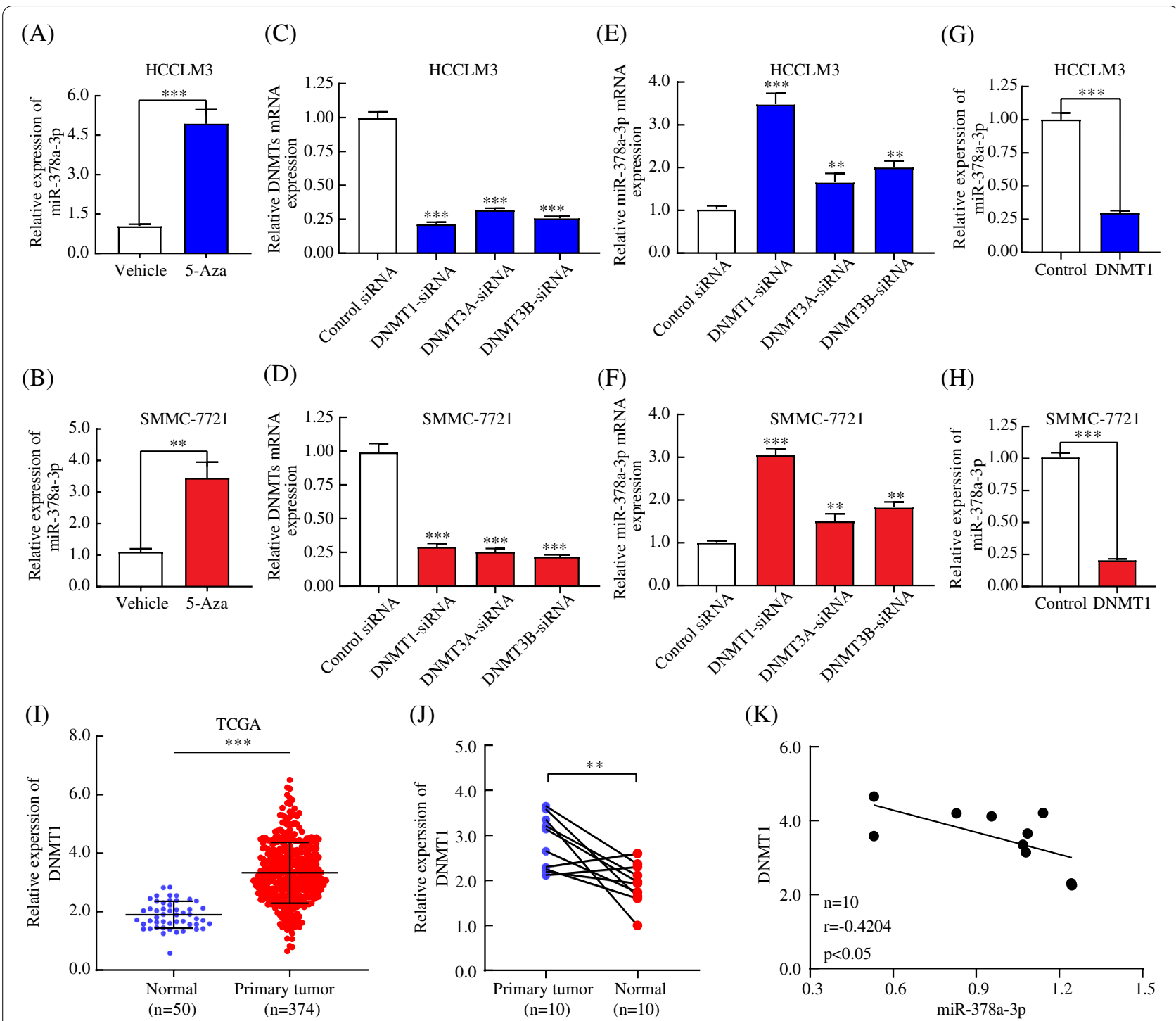

Fig. 6 miR-378a-3p is hypermethylated by DNMT1 and silenced in HCC tissues and cells. A, B miR-378a-3p mRNA expression was detected in HCCLM3 and SMMC-7721 cells treated with $10 \mu \mathrm{M}$ 5-Aza-dC for 48 h. C, D HCCLM3 and SMMC-7721 cells were transfected with DNMTs siRNA for 48 h, DNMTs mRNA expression was measured by qRT-PCR. E, F HCCLM3 and SMMC-7721 cells were transfected with DNMTs siRNA for 48 h, and miR-378a-3p mRNA expression was measured. G, H miR-378a-3p mRNA expression was detected in HCC cells transfected with pcDNA-DNMT1 and pCDNA-NC. I, JThe mRNA expression of DNMT1 in the TCGA database and in 10 paired HCC and adjacent normal tissues is shown. $\mathbf{K}$ The relationship between DNMT1 and miR-378a-3p in 10 matched fresh HCC samples is shown. ${ }^{*} P<0.05 ;{ }^{* *} P<0.01 ;{ }^{* * *} P<0.001$

alpha (DNMT3A), and DNA methyltransferase 3 beta (DNMT3B) in HCC cells using specific small interfering RNAs (siRNAs) (Fig. 6C, D). The relative miR-378a-3p mRNA level of HCC cells transfected with DNMT1 siRNA, but not those transfected with DNMT3A siRNA and DNMT3B siRNA was obviously increased (Fig. 6E, F). Moreover, overexpression of DNMT1 significantly suppressed miR-378a-3p expression (Fig. 6G, H). To further test this speculation, we evaluated the expression level of DNMT1 in HCC patients with the TCGA database (Fig. 6I). We also examined the expression level of DNMT1 in 10 pairs of clinical HCC and normal tissues. The results revealed that DNMT1 was generally expressed at a higher level in HCC tissues (Fig. 6J). Spearman's rank correlation analysis revealed a negative correlation between DNMT1 and miR-378a-3p expression (Fig. 6K). The above results suggested that DNMT1 significantly increased the hypermethylation of the miR-378a-3p promoter and suppressed the expression of miR-378a-3p. 


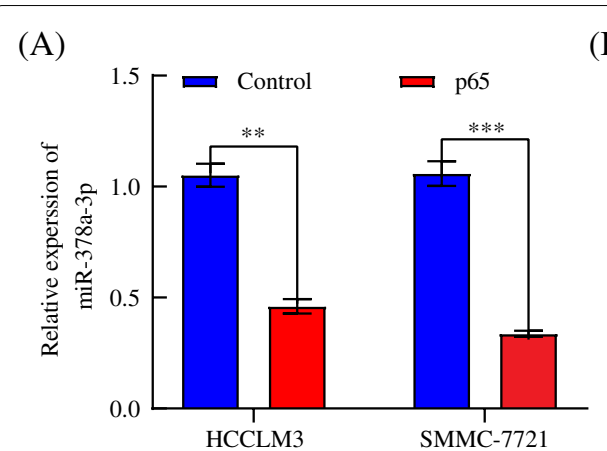

(D)

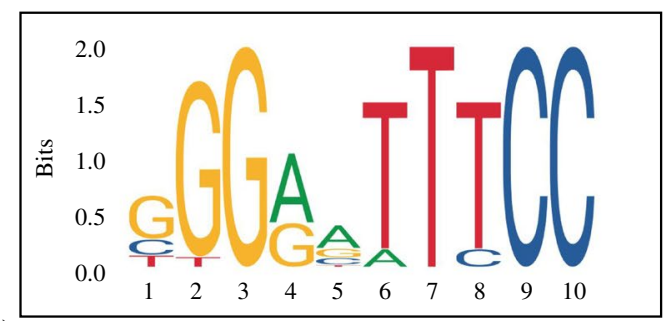

(E)

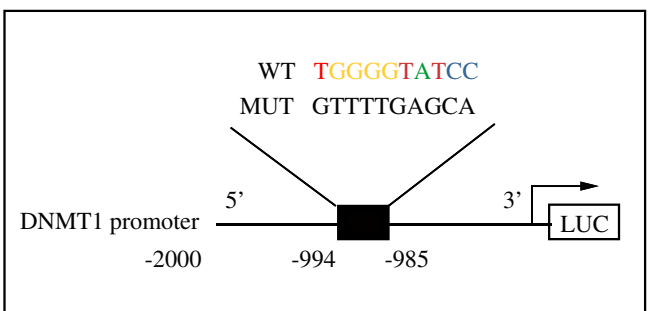

(B)

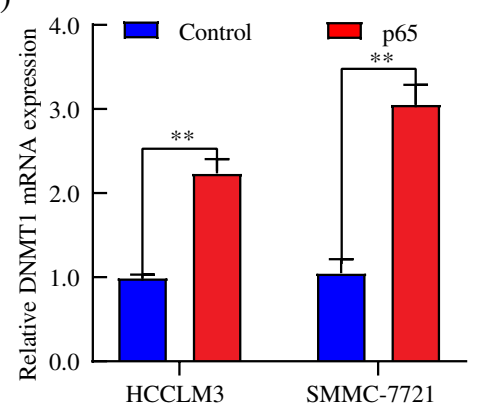

(F)

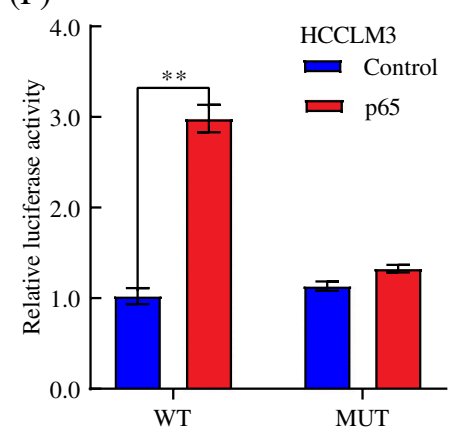

(G)

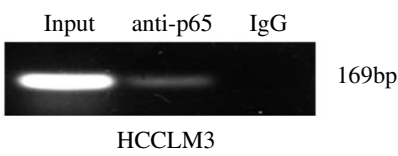

(C)
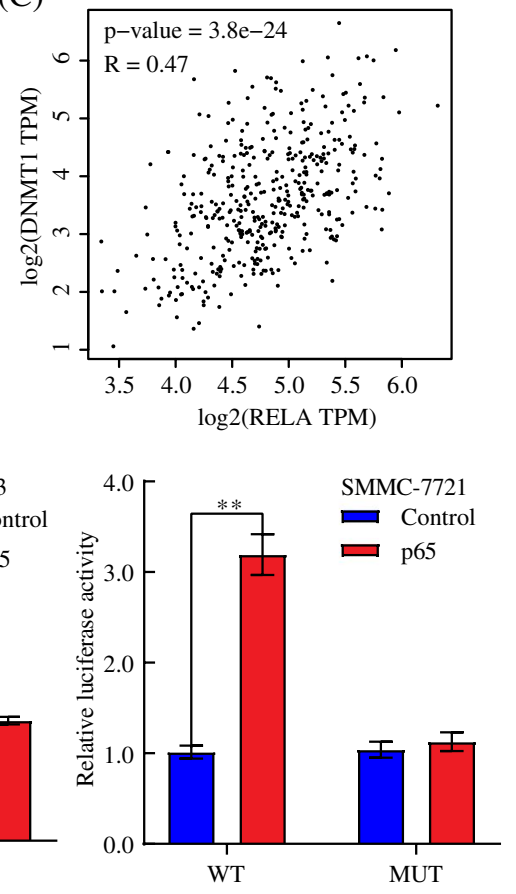

Input anti-p65 IgG

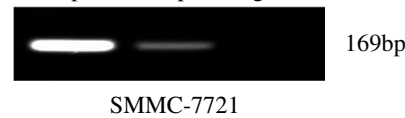

Fig. 7 p65 promoted DNMT1 transcription and induced miR-378a-3p silencing mediated by DNA hypermethylation. A mRNA expression of miR-378a-3p was detected in different HCC cells transfected with control or p65. B The mRNA levels of DNMT1 were detected in HCC cells transfected with control or p65. C The relationship between DNMT1 and p65 in the GEPIA database. D, E Schematic diagram of binding sites from the JASPAR databases. F, G Detecting the function of p65 on the DNMT1 promoter by luciferase reporter and ChIP assays. ${ }^{*} P<0.05$; ${ }^{* *} P<0.01$; ${ }^{* * *} P<0.001$

p65 promoted DNMT1 transcription and induced miR-378a-3p silencing mediated by DNA hypermethylation Consistent with our results, silencing miR-378a-3p can activate p65, which is a well-known transcription factor and is involved in tumorigenesis and development [38]. Interestingly, we found that p65 overexpression could downregulate the miR-378a-3p expression and upregulate DNMT1 mRNA expression in HCC cells (Fig. 7A, B). GEPIA database showed that 065 was positively correlated with DNMT1 in HCC (Fig. 7C). Based on this phenomenon, we assumed that p65 could transcription activate DNMT1, the methyltransferase of miR-378a-3p. To prove this assumption, we analyzed the DNMT1 promoter and identified potential binding sites for p65 (Fig. 7D) and then constructed vectors containing wild-type or mutant promoters of DNMT1 for a luciferase reporter assay (Fig. 7E). We found that the transfection of p65 significantly enhanced the luciferase activity of the DNMT1 WT reporter, whereas this effect was completely reversed by the mutant reporter, indicating that this site was the key region of p65 mediated DNMT1 upregulation (Fig. 7F). The results of the ChIP assay determined that p65 directly bound to the DNMT1 promoter in HCC cells (Fig. 7G). Taken together, these results suggested that DNMT1 could be activated by p 65 and cause the epigenetic silencing of miR-378a-3p.

\section{The in vivo role of DNMT1/miR-378a-3p/TRAF1/p65 in regulating $\mathrm{HCC}$ angiogenesis}

Finally, we evaluated the effect of the DNMT1/miR378a-3p/TRAF1/p65 axis on tumor growth and angiogenesis in vivo. The results showed that the miR-378a-3p agomir significantly inhibited tumor growth compared with the agomir-NC (Fig. 8A-C). IHC was carried out to detect DNMT1, TRAF1, p65, VEGF and CD34 in tumor 
tissues. The agomir-NC group showed higher expression of DNMT1, TRAF1, p65, VEGF and CD34 than miR-378a-3p agomir group (Fig. 8D). To investigate the clinical significance of the axis in promoting $\mathrm{HCC}$ angiogenesis, we examined the expression of miR-378a-3p, DNMT1, TRAF1, p65, VEGF and CD34 in HCC tissues and determined their relevance in HCC. The expression of miR-378a-3p was negatively correlated with the expression of DNMT1, TRAF1, p65, VEGF and CD34 in 10 matched fresh HCC samples (Fig. 8E, Fig. S4A-C). Moreover, we analyzed the correlation of miR-378a-3p, DNMT1, TRAF1 and VEGFA in TCGA data and found that the expression of miR-378a-3p was significantly inversely correlated with that of DNMT1, TRAF1, and VEGFA in HCC (Fig. S4D-F). Furthermore, we found that patients with HCC with high DNMT1, TRAF1 or VEGF mRNA levels had poorer survival rate via TCGA and SurvExpress databases (Fig. S4G-I). These data suggest that the DNMT1/miR-378a-3p/TRAF1/p65 axis inhibits HCC progression partly through restraining angiogenesis.

\section{Discussion}

Angiogenesis plays pivotal roles in tumor progression and metastasis. Thus, it is important to investigate the role of miR-378a-3p in regulating HCC angiogenesis to develop therapeutic interventions. In this study, we found that the expression of miR-378a-3p was downregulated in HCC and was related to a poor prognosis. The expression of miR-378a-3p exerted a significant effect on angiogenesis according to a series of experiments in vitro and in vivo. Mechanistically, we also proved a positive feedback loop towards the hypermethylation of miR-378a-3p promoted by p65-mediated upregulation of DNMT1. A working model of our study has been summarized (Fig. 8F). Thus, we confirmed a new role for miR-378a-3p plays as an antiangiogenic factor in HCC, which provides a promising means for $\mathrm{HCC}$ treatment.

TRAF1, a member of the TRAF family, is known to regulate the cascade of canonical and non-canonical NF- $\mathrm{KB}$ signaling. Compared with the other members, TRAF1 has received more attention due to its lack of RING and zinc finger structures [39]. The upregulated antiapoptotic protein TRAF1 activates the PI3K/Akt/ NF- $\mathrm{kB}$ signaling pathway in non-small cell lung cancer (NSCLC) [40]. TRAF1 is necessary for the development of UV radiation-induced skin cancer, and the deletion of TRAF1 in mice has been shown to significantly inhibit the formation of skin tumor [41]. Additionally, miR-483 has been shown to inhibit the proliferation and migration of colorectal cancer cells by targeting TRAF1 [42]. Studies have shown that miR-127-5p alleviates severe pneumonia by targeting TRAF1 to inactivate the Akt and NF- $\mathrm{kB}$ signaling pathways [43]. In our study, TRAF1 was confirmed as the downstream regulator of miR378a-3p. Additionally, miR-378a-3p could negatively regulate the expression of TRAF1. These data further suggested that miR-378a-3p is inversely correlated with TRAF1 in HCC.

DNA methylation is one of the most important epigenetic modifications and is involved in various human diseases [44]. DNA methyltransferases (DNMTs) are a vital epigenetic family of enzymes that catalyze and maintain DNA methylation. Studies have identified three types of DNMTs with specific biological functions: DNMT1, DNMT3A, and DNMT3B. Compared with DNMT3A and DNMT3B, DNMT1 plays a more vital biological role [45]. Numerous studies have found that DNMT1 is associated with abnormal DNA methylation, and elevated expression of DNMT1 has been shown to promote the occurrence and development of cancers of the esophagus, breast, pancreas, thyroid, and colon [46]. Enhancer of Zeste homologue 2 (EZH2) has been shown to recruit DNMT1 to methylate the CpG island of the miR-484 promoter, which negatively regulates the Wnt/MAPK and TNF signaling pathways by upregulating the expression of HNF1A and MMP14, respectively, to inhibit the growth and metastasis of cervical cancer [47]. Jiang et al. found that ARID2 inhibited the epithelial-mesenchymal transition (EMT) of HCC cells by recruiting DNMT1 to the Snail promoter region, inducing promoter methylation and inhibiting Snail transcription [48]. Our results reveal a new mechanism indicating DNMT1induced regulation of the downregulated expression of miR-378a-3p.

The expression of DNMT1 is regulated by multiple factors. Ubiquitinated histone $\mathrm{H} 3$ peptide $(\mathrm{H} 3 \mathrm{Ub})$ stimulates the maintenance activity of DNMT1 by increasing its methylation processivity. The SET and RING fingerassociated domain (SRA) domains of ubiquitin-like with PHD and ring finger domain 1 (Uhrf1) additively stimulate DNMT1 activity with H3Ub peptides [49]. Deletion

\footnotetext{
(See figure on next page.)

Fig. 8 In vivo role of DNMT1/miR-378a-3p/TRAF1/p65 in regulating HCC angiogenesis. A-C Tumor growth of mice subcutaneously implanted with treated HCCLM3 cells. Tumor volume and weight were measured, and tumor size is shown. D Immunohistochemical staining of CD34, DNMT1, TRAF1, p65 and VEGF in the tumors from subcutaneously implanted mice. E FISH assay for miR-378a-3p and immunohistochemical staining for DNMT1, TRAF1, p65, VEGF and CD34 were performed on 10 human HCC specimens. F A working model showing how miR-378a-3p inhibits HCC tumor angiogenesis by inactivating the NF-KB signaling pathway. ${ }^{*} P<0.05 ;{ }^{* *} P<0.01 ;{ }^{* *} P<0.001$
} 
(A)

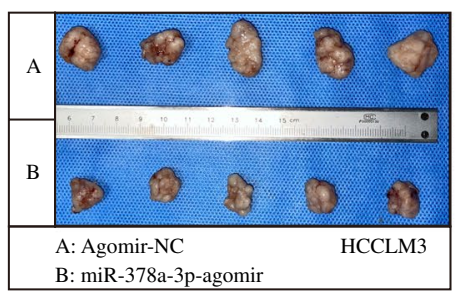

(B)

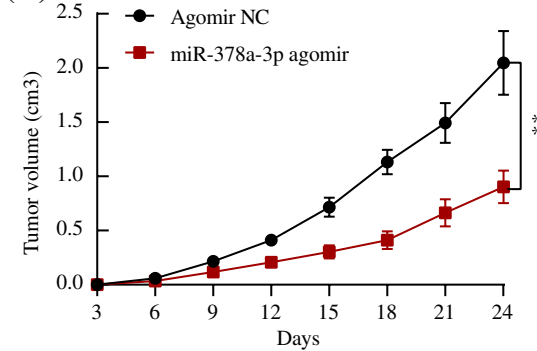

(C)

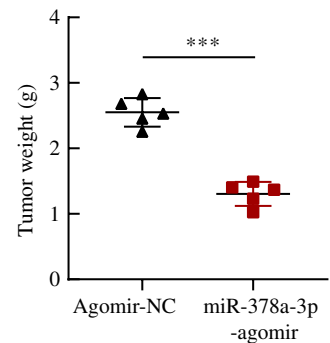

(D)

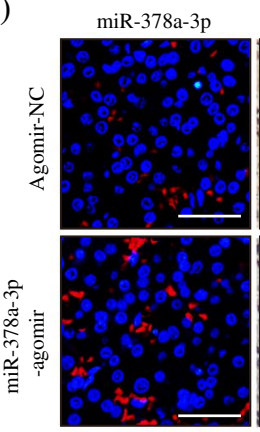

DNMT1

$$
\text { TRAF1 }
$$

p65

VEGF

$\mathrm{CD} 34$
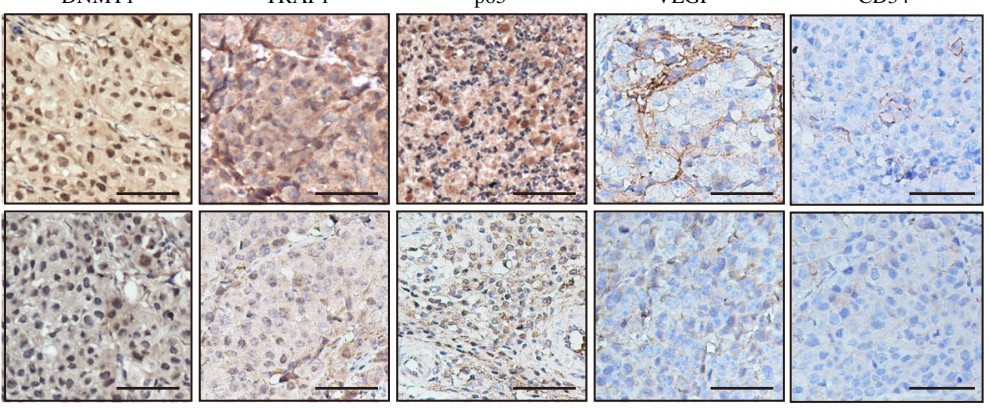

(E)

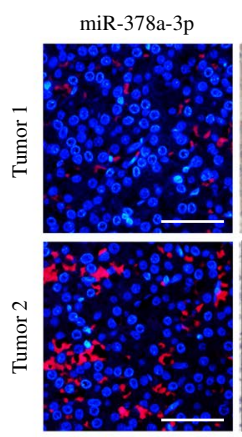

DNMT1

TRAF1

p65

VEGF

CD34
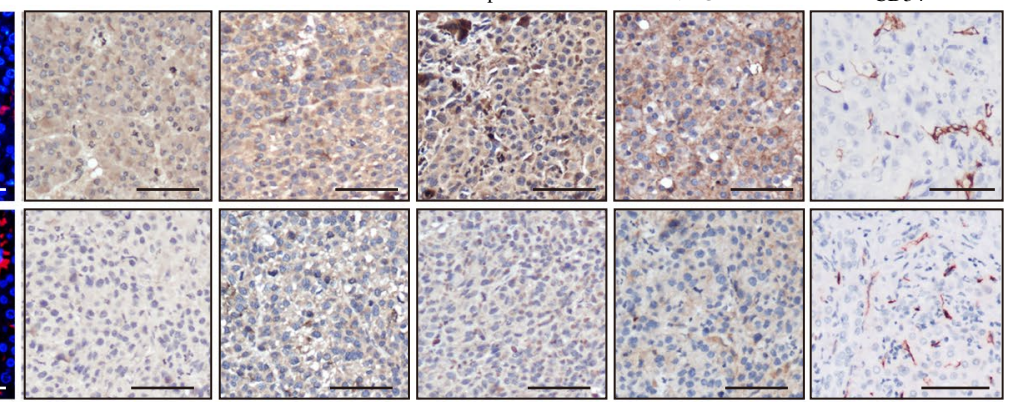

$(\mathrm{F})$

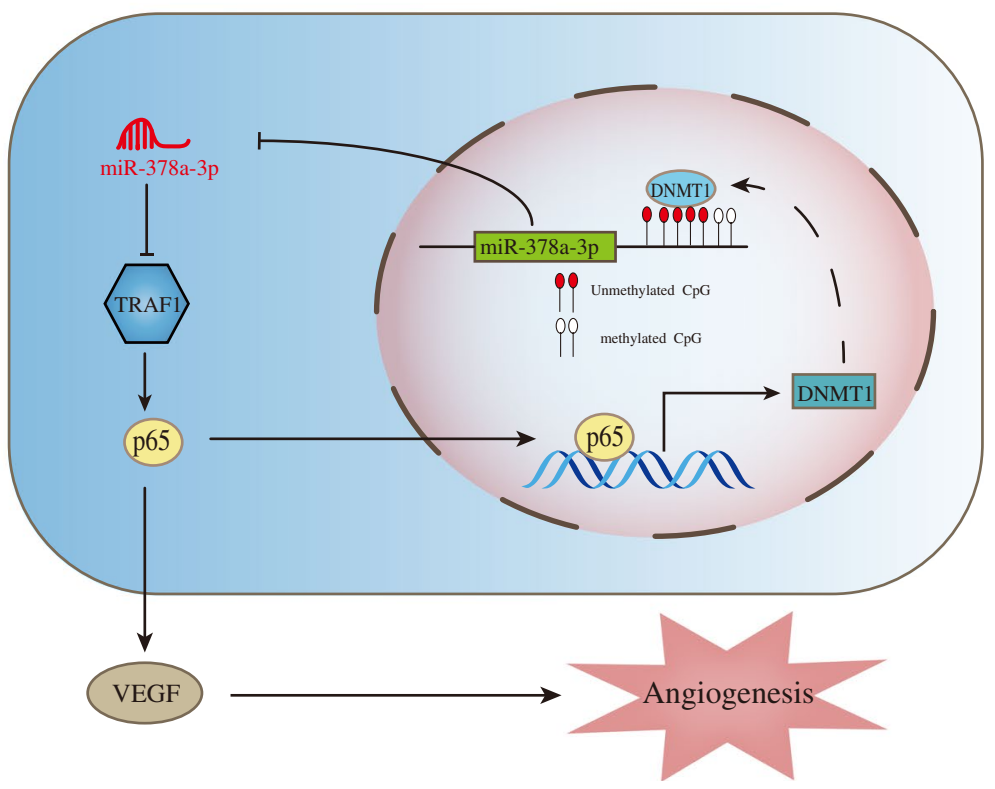

Fig. 8 (See legend on previous page.) 
of lysine-specific histone demethylase 1 (LSD1) induces the loss of DNA methylation. This loss correlates with a decrease in DNMT1 protein expression, as a result of reduced DNMT1 stability [50]. Multiple transcription factors, including E2F1 and SP1, mediate the transcriptional activation of DNMT1 by the activating the MEK/ ERK pathway [51]. In lung cancer, p65 is known to directly recruit DNMT1 to chromatin to enhance the methylation of the BRMS1 promoter; thus, acting as a transcriptional suppressor [52]. Therefore, we hypothesized that p65 induced DNMT1 transcription by promoting the activation of the promoter of DNMT1 in HCC. These results suggested that DNA promoter methylation might be a common approach of miR-378a-3p silencing in HCC. Downregulated expression of miR-378a-3p could promote TRAF1 expression, which leads to the upregulation of $\mathrm{NF}-\mathrm{KB}$ signaling, thereby promoting a series of angiogenic effects in HCC cells. Interestingly, activated NF- $\mathrm{kB}$ could then in turn up-regulate DNMT1 expression, which forms a positive feedback loop that increased the methylation level of the miR-378a-3p promoter, thereby enhancing the angiogenesis effect of miR-378a-3p silencing and TRAF1 upregulation.

\section{Conclusion}

In conclusion, our study revealed that miR-378a-3p is a potential predictor and therapeutic target for the treatment of HCC. Low miR-378a-3p expression was found to be associated with higher MVD and poor survival outcome in HCC patients. We found that DNA hypermethylationinduced silencing of miR-378a-3p facilitates HCC angiogenesis by upregulating TRAF1 and NF- $\mathrm{kB}$ signaling. As a transcriptional coactivator, $\mathrm{p} 65$ promotes DNMT1 expression, which positively regulates miR-378a-3p promoter methylation.

\footnotetext{
Abbreviations

HCC: Hepatocellular carcinoma; CCK-8: Cell Counting Kit-8; ChIP: Chromatin immunoprecipitation; FISH: Fluorescence in situ hybridization; MVD: Microvascular density; HUVECs: Human umbilical vein endothelial cells; TRAF1: TNF receptor associated factor 1; VEGF: Vascular endothelial growth factor; DNMT1: DNA methyltransferase 1; REC8: Meiotic recombination protein; PDSS2-DEL2: Prenyl diphosphate synthase subunit 2; MicroRNAs: MiRNAs; KLK4: Kallikreinrelated peptidase 4; MAP K1: Mitogen-activated protein kinase 1; GRB2: Growth factor receptor bound protein 2; FBS: Fetal bovine serum; NSCLC: Nonsmall cell lung cancer; qRT-PCR: Quantitative reverse; transcriptase polymerase chain reaction; GEO: Gene Expression Omnibus; TCGA: The Cancer Genome Atlas; GEPIA: Gene Expression Profiling Interactive Analysis; STRING: Search Tool for the Retrieval of Interacting Genes/Proteins; RNA-seq: RNA sequencing; OS: Overall survival; DFS: Disease-free survival; EZH2: Enhancer of Zeste Homolog 2; UTR: Untranslated region; DEGs: Differentially expressed genes; LPS: Lipopolysaccharide; DNMT3A: DNA methyltransferase 3 alpha; DNMT3B: DNA methyltransferase 3 beta; siRNAs: Small interfering RNAs; EMT: Epithelialmesenchymal transition; $\mathrm{H} 3 \mathrm{Ub}$ : $\mathrm{H} 3$ peptide ubiquitinated; SRA: SET and RING finger-associated; Uhrf1: Ubiquitin like with PHD and ring finger domains 1; LSD1: Lysine-specific histone demethylase 1 ..
}

\section{Supplementary Information}

The online version contains supplementary material available at https://doi. org/10.1186/s13046-021-02110-6.

Additional file 1 : Table S1. Sequences of siRNAs.

Additional file $\mathbf{2}$ : Table S2. Sequences of primers used for qRT-PCR and ChIP.

Additional file 3 : Fig. S1. miR-378a-3p expression inhibited HCC angiogenesis in vitro and in vivo. (A) MHCC-97H and MHCC-97 L cells were transfected with miR-378a-3p mimic, mimic-NC, inhibitor, or inhibitor-NC and analyzed by qRT-PCR. (B-F) Treated HUVECs were evaluated by the CCK-8 and colony formation assays to analyze cell viability. (G-M) Wound healing, invasion and tube formation assays were performed to analyze angiogenesis. (N) The VEGF protein concentration in conditioned medium of treated MHCC-97H and MHCC-97 L cells was detected by ELISA. ${ }^{*} P<0.05$; ${ }^{* *} P<0.01$; ${ }^{* *} P<0.001$.

Additional file 4 : Fig. S2. miR-378a-3p suppressed endothelial cell proliferation, migration, invasion and angiogenesis by directly regulating NF-KB. (A-D) HUVECs were co-cultured with treated HCCLM3 and SMMC-7721 cells for $48 \mathrm{~h}$. Treated HUVECs were evaluated by the CCK-8 and colony formation assays to analyze cell viability. (E-H) Wound healing and invasion assays were performed. (I, J) HUVEC tube formation assays were performed and cultured with conditioned supernatant collected from HCC cells. (K) The VEGF protein concentration in the conditioned medium of treated HCC cells was detected by ELISA. ${ }^{*} P<0.05$; ${ }^{* *} P<0.01$; ***P $P<0.001$

Additional file $\mathbf{5}$ : Fig. S3. miR-378a-3p suppressed tumor progression by directly regulating NF-KB. (A, B) The protein levels of TRAF1 and NF-KB were detected in HCCLM3 and SMMC-7721 cells treated with miR-NC, miR-378a-3p, LPS, and anti-miR-NC, anti-miR-378a-3p, and SN50. ${ }^{*} P<0.05$; ${ }^{* *} P<0.01$; ${ }^{* *} P<0.001$

Additional file 6 : Fig. S4. In vivo role of DNMT1/miR-378a-3p/TRAF1/ p65 in regulating HCC angiogenesis. (A, B, C) Correlation analysis of miR378a-3p and DNMT1, TRAF1 and VEGFA 10 human HCC specimens. (D, E, F) Correlation analysis of miR-378a-3p and DNMT1, TRAF1 and VEGFA in $\mathrm{HCC}$ with data from the TCGA dataset. (G, $\mathbf{H}, \mathbf{I})$ OS analysis according to DNMT1 and VEGFA expression in patients with HCC in the TCGA dataset. ${ }^{*} P<0.05$; ${ }^{* *} P<0.01$; ${ }^{* *} P<0.001$.

\section{Acknowledgements}

We thank the Liver Cancer Institute of ZhongShan Hospital (Shanghai, China) for the gift of the MHCC-97L, MHCC-97H and HCCLM3 cell lines.

\section{Authors' contributions}

WJX and YLH wrote the original manuscript and analyzed the data. BZ, JJC, YF, JLY, HH and CWY performed the experiments and analyzed the data. All authors read and approved the final manuscript.

\section{Funding}

This work was supported by the National Natural Science Foundation of China (81672409), the Foundation of Nantong science and technology bureau (MSZ19204), the Foundation of Nantong science and technology bureau (MS12019026), and the Foundation of Nantong science and technology bureau (JC2019033).

\section{Availability of data and materials}

The datasets used or analysed during the current study are available from the corresponding author on reasonable request.

\section{Declarations}

\section{Ethics approval and consent to participate}

This study was approved by the Affiliated Hospital of Nantong University following the principles of the Helsinki Declaration. All participants provided written informed consent to take part in the study. In animal experiments, we 
comply with the ARRIVE guidelines, the UK Animals (Scientific Procedures) Act, 1986 and associated guidelines, EU Directive 2010/63/EU for animal experiments, or the National Institutes of Health guide for the care and use of Laboratory animals (NIH Publications No. 8023, revised 1978). The mice purchased are male. In addition, animal experiments were performed using protocols approved by the Animal Center of the Medical College of Nantong University.

\section{Consent for publication}

Not applicable.

\section{Competing interests}

The authors confirm that there are no conflicts of interest.

\section{Author details}

${ }^{1}$ Department of General Surgery, Affiliated Hospital of Nantong University, 20 Xisi Street, Nantong 226001, Jiangsu, China. ${ }^{2}$ Research Center of Clinical Medicine, Affiliated Hospital of Nantong University, 20 Xisi Street, Nantong 226001, Jiangsu, China. ${ }^{3}$ Medical school, Nantong University, 19 Qixiu Road, Nantong 226001, Jiangsu, China. ${ }^{4}$ Department of Pathology, Affiliated Hospital of Nantong University, 20 Xisi Street, Nantong 226001, Jiangsu, China. ${ }^{5}$ Department of Hepatobiliary and Pancreatic Surgery, Leicester General Hospital, University of Leicester, Gwendolen Road, Leicester LE5 4PW, UK.

Received: 1 June 2021 Accepted: 17 September 2021

Published online: 08 November 2021

\section{References}

1. Lee SE, Alcedo KP, Kim HJ, Snider NT. Alternative splicing in hepatocellular carcinoma. Cell Mol Gastroenterol Hepatol. 2020;10(4):699-712. https://doi.org/10.1016/j.jcmgh.2020.04.018.

2. Llovet JM, Zucman-Rossi J, Pikarsky E, Sangro B, Schwartz M, Sherman M, et al. Hepatocellular carcinoma. Nat Rev Dis Primers. 2016;2:16018. https://doi.org/10.1038/nrdp.2016.18.

3. Alsaab HO, Al-Hibs AS, Alzhrani R, Alrabighi KK, Alqathama A, Alwithenani $A$, et al. Nanomaterials for antiangiogenic therapies for cancer: a promising tool for personalized medicine. Int J Mol Sci. 2021;22(4). https://doi.org/10.3390/ijms22041631.

4. Sbenati RM, Zaraei SO, El-Gamal MI, Anbar HS, Tarazi H, Zoghbor MM et al. Design, synthesis, biological evaluation, and modeling studies of novel conformationally-restricted analogues of sorafenib as selective kinase-inhibitory antiproliferative agents against hepatocellular carcinoma cells. Eur J Med Chem. 2021;210:113081. https://doi.org/10. 1016/j.ejmech.2020.113081.

5. Eso Y. Targeting angiogenesis for advanced hepatocellular carcinoma. Intern Med. 2021;60(3):321-2. https://doi.org/10.2169/internalmedicine. 5923-20.

6. Zhu XD, Tang ZY, Sun HC. Targeting angiogenesis for liver cancer: past, present, and future. Genes Dis. 2020;7(3):328-35. https://doi.org/10. 1016/j.gendis.2020.03.010.

7. Zhou W, Yang L, Nie L, Lin H. Unraveling the molecular mechanisms between inflammation and tumor angiogenesis. Am J Cancer Res. 2021;11(2):301-17.

8. Tang X, Cao T, Zhu Y, Zhang L, Chen J, Liu T, et al. PIM2 promotes hepatocellular carcinoma tumorigenesis and progression through activating NF-kappaB signaling pathway. Cell Death Dis. 2020;11(7):510. https://doi. org/10.1038/s41419-020-2700-0

9. Xia Y, Shen S, Verma IM. NF-kappaB, an active player in human cancers. Cancer Immunol Res. 2014;2(9):823-30. https://doi.org/10.1158/23266066.CIR-14-0112.

10. Mu HQ, He YH, Wang SB, Yang S, Wang YJ, Nan CJ, et al. MiR-130b/ TNF-alpha/NF-kappaB/NEGFA loop inhibits prostate cancer angiogenesis. Clin Transl Oncol. 2020;22(1):111-21. https://doi.org/10.1007/ s12094-019-02217-5.

11. Liang S, Chen Z, Jiang G, Zhou Y, Liu Q, Su Q, et al. Activation of GPER suppresses migration and angiogenesis of triple negative breast cancer via inhibition of NF-kappaB/IL-6 signals. Cancer Lett. 2017;386:12-23. https:// doi.org/10.1016/j.canlet.2016.11.003.

12. Wang R, Ma Y, Zhan S, Zhang G, Cao L, Zhang X, et al. B7-H3 promotes colorectal cancer angiogenesis through activating the NF-kappaB pathway to induce VEGFA expression. Cell Death Dis. 2020;11(1):55. https://doi.org/10.1038/s41419-020-2252-3.

13. Azoitei N, Becher A, Steinestel K, Rouhi A, Diepold K, Genze F, et al. PKM2 promotes tumor angiogenesis by regulating HIF-1alpha through NF-kappaB activation. Mol Cancer. 2016;15:3. https://doi.org/10.1186/ s12943-015-0490-2.

14. Liu M, Xu W, Su M, Fan P. REC8 suppresses tumor angiogenesis by inhibition of NF-kappaB-mediated vascular endothelial growth factor expression in gastric cancer cells. Biol Res. 2020;53(1):41. https://doi.org/ 10.1186/s40659-020-00307-1.

15. Zeng T, Tang Z, Liang L, Suo D, Li L, Li J, et al. PDSS2-Del2, a new variant of PDSS2, promotes tumor cell metastasis and angiogenesis in hepatocellular carcinoma via activating NF-kappaB. Mol Oncol. 2020;14(12):3184-97. https://doi.org/10.1002/1878-0261.12826.

16. Annese T, Tamma R, De Giorgis M, Ribatti D. microRNAs biogenesis, functions and role in tumor angiogenesis. Front Oncol. 2020;10:581007. https://doi.org/10.3389/fonc.2020.581007.

17. Gallach S, Calabuig-Farinas S, Jantus-Lewintre E, Camps C. MicroRNAs: promising new antiangiogenic targets in cancer. Biomed Res Int. 2014;2014:878450. https://doi.org/10.1155/2014/878450.

18. Machado IF, Teodoro JS, Palmeira CM, Rolo AP. miR-378a: a new emerging microRNA in metabolism. Cell Mol Life Sci. 2020;77(10):1947-58. https:// doi.org/10.1007/s00018-019-03375-Z.

19. Zhang T, Shi H, Liu N, Tian J, Zhao X, Steer CJ, et al. Activation of microRNA-378a-3p biogenesis promotes hepatic secretion of VLDL and hyperlipidemia by modulating ApoB100-Sortilin1 axis. Theranostics. 2020;10(9):3952-66. https://doi.org/10.7150/thno.39578.

20. Krist B, Podkalicka P, Mucha O, Mendel M, Sepiol A, Rusiecka OM, et al. miR-378a influences vascularization in skeletal muscles. Cardiovasc Res. 2020;116(7):1386-97. https://doi.org/10.1093/cvr/cvz236.

21. Fu H, Zhang J, Pan T, Ai S, Tang L, Wang F. miR378a enhances the sensitivity of liver cancer to sorafenib by targeting VEGFR, PDGFRbeta and cRaf. Mol Med Rep. 2018;17(3):4581-8. https://doi.org/10.3892/mmr. 2018.8390.

22. Tanaka H, Hazama S, lida M, Tsunedomi R, Takenouchi H, Nakajima $M$, et al. miR-125b-1 and miR-378a are predictive biomarkers for the efficacy of vaccine treatment against colorectal cancer. Cancer Sci. 2017;108(11):2229-38. https://doi.org/10.1111/cas.13390.

23. $\mathrm{Xu} Z \mathrm{ZH}$, Yao TZ, Liu W. miR-378a-3p sensitizes ovarian cancer cells to cisplatin through targeting MAPK1/GRB2. Biomed Pharmacother. 2018;107:1410-7. https://doi.org/10.1016/j.biopha.2018.08.132.

24. Ma J, Lin J, Qian J, Qian W, Yin J, Yang B, et al. MiR-378 promotes the migration of liver cancer cells by down-regulating Fus expression. Cell Physiol Biochem. 2014;34(6):2266-74. https://doi.org/10.1159/000369669.

25. Pogribny IP. MicroRNA dysregulation during chemical carcinogenesis. Epigenomics. 2009;1(2):281-90. https://doi.org/10.2217/epi.09.17.

26. Wang Q, Gao G, Zhang T, Yao K, Chen H, Park MH, et al. TRAF1 is critical for regulating the BRAF/MEK/ERK pathway in non-small cell lung carcinogenesis. Cancer Res. 2018;78(14):3982-94. https://doi.org/10.1158/00085472.CAN-18-0429.

27. Liu H, Song Y, Qiu H, Liu Y, Luo K, Yi Y, et al. Downregulation of FOXO3a by DNMT1 promotes breast cancer stem cell properties and tumorigenesis. Cell Death Differ. 2020;27(3):966-83. https://doi.org/10.1038/ s41418-019-0389-3.

28. Hu YL, Feng Y, Ma P, Wang F, Huang H, Guo YB, et al. HAX-1 promotes the migration and invasion of hepatocellular carcinoma cells through the induction of epithelial-mesenchymal transition via the NF-kappaB pathway. Exp Cell Res. 2019;381(1):66-76. https://doi.org/10.1016/j.yexcr.2019.04.030.

29. Lu Y, Guo G, Hong R, Chen X, Sun Y, Liu F, et al. LnCRNA HAS2-AS1 promotes glioblastoma proliferation by sponging miR-137. Front Oncol. 2021;11:634893. https://doi.org/10.3389/fonc.2021.634893.

30. Liu JZ, Hu YL, Feng Y, Guo YB, Liu YF, Yang JL, et al. Rafoxanide promotes apoptosis and autophagy of gastric cancer cells by suppressing PI3K / Akt/mTOR pathway. Exp Cell Res. 2019;385(2):111691. https://doi.org/10. 1016/j.yexcr.2019.111691.

31. Mazzanti R, Messerini L, Comin CE, Fedeli L, Ganne-Carrie N, Beaugrand M. Liver angiogenesis as a risk factor for hepatocellular carcinoma development in hepatitis C virus cirrhotic patients. World J Gastroenterol. 2007;13(37):5009-14. https://doi.org/10.3748/wjg.v13.i37.5009.

32. Qu F, Zhu B, Hu YL, Mao QS, Feng Y. LncRNA HOXA-AS3 promotes gastric cancer progression by regulating miR-29a-3p/LTbetaR and activating 
NF-kappaB signaling. Cancer Cell Int. 2021;21(1):118. https://doi.org/10. 1186/s12935-021-01827-w.

33. Fu C, Li D, Zhang X, Liu N, Chi G, Jin X. LncRNA PVT1 facilitates tumorigenesis and progression of glioma via regulation of MiR-128-3p/GREM1 Axis and BMP signaling pathway. Neurotherapeutics. 2018;15(4):1139-57. https://doi.org/10.1007/s13311-018-0649-9.

34. Hu YL, Feng Y, Chen YY, Liu JZ, Su Y, Li P, et al. SNHG16/miR-605-3p/TRAF6/ NF-kappaB feedback loop regulates hepatocellular carcinoma metastasis. J Cell Mol Med. 2020;24(13):7637-51. https://doi.org/10.1111/jcmm. 15399.

35. Guo F, Sun A, Wang W, He J, Hou J, Zhou P, et al. TRAF1 is involved in the classical NF-kappaB activation and CD30-induced alternative activity in Hodgkin's lymphoma cells. Mol Immunol. 2009;46(13):2441-8. https://doi. org/10.1016/j.molimm.2009.05.178.

36. Shi W, Tang T, Li X, Deng S, Li R, Wang Y, et al. Methylation-mediated silencing of miR-133a-3p promotes breast cancer cell migration and stemness via miR-133a-3p/MAML1/DNMT3A positive feedback loop. J Exp Clin Cancer Res. 2019;38(1):429. https://doi.org/10.1186/ s13046-019-1400-z.

37. Zeng B, Zhang X, Zhao J, Wei Z, Zhu H, Fu M, et al. The role of DNMT1/ hsa-miR-124-3p/BCAT1 pathway in regulating growth and invasion of esophageal squamous cell carcinoma. BMC Cancer. 2019;19(1):609. https://doi.org/10.1186/s12885-019-5815-x.

38. Mori Y, Akita K, Tanida S, Ishida A, Toda M, Inoue M, et al. MUC1 protein induces urokinase-type plasminogen activator (UPA) by forming a complex with NF-kappaB p65 transcription factor and binding to the UPA promoter, leading to enhanced invasiveness of cancer cells. J Biol Chem. 2014;289(51):35193-204. https://doi.org/10.1074/jbc.M114.586461.

39. Zapata JM, Reed JC. TRAF1: lord without a RING. Sci STKE. 2002;2002(133):pe27. https://doi.org/10.1126/stke.2002.133.pe27.

40. Song L, Xiong H, Li J, Liao W, Wang L, Wu J, et al. Sphingosine kinase-1 enhances resistance to apoptosis through activation of PI3K/Akt/NFkappaB pathway in human non-small cell lung cancer. Clin Cancer Res. 2011;17(7):1839-49. https://doi.org/10.1158/1078-0432.CCR-10-0720.

41. Yamamoto H, Ryu J, Min E, Oi N, Bai R, Zykova TA, et al. TRAF1 is critical for DMBA/solar UVR-induced skin carcinogenesis. J Invest Dermatol. 2017;137(6):1322-32. https://doi.org/10.1016/j.jid.2016.12.026.

42. Niu ZY, Li WL, Jiang DL, LiYS, Xie XJ. Mir-483 inhibits colon cancer cell proliferation and migration by targeting TRAF1. Kaohsiung J Med Sci. 2018;34(9):479-86. https://doi.org/10.1016/j.kjms.2018.04.005.
43. Chen C, Lin S, Zhou L, Wang J, Chen J, Yu R, et al. MicroRNA-127-5p attenuates severe pneumonia via tumor necrosis factor receptor-associated factor 1. Exp Ther Med. 2020;20(3):2856-62. https://doi.org/10.3892/ etm.2020.8997.

44. Kulis M, Esteller M. DNA methylation and cancer. Adv Genet. 2010;70:2756. https://doi.org/10.1016/B978-0-12-380866-0.60002-2.

45. Ren W, Gao L, Song J. Structural basis of DNMT1 and DNMT3A-mediated DNA methylation. Genes (Basel). 2018;9(12). https://doi.org/10.3390/ genes9120620.

46. Xu X, Nie J, Lu L, Du C, Meng F, Song D. LINC00337 promotes tumor angiogenesis in colorectal cancer by recruiting DNMT1, which suppresses the expression of CNN1. Cancer Gene Ther. 2020. https://doi.org/10.1038/ s41417-020-00277-2.

47. Hu Y, Wu F, Liu Y, Zhao Q, Tang H. DNMT1 recruited by EZH2-mediated silencing of miR-484 contributes to the malignancy of cervical cancer cells through MMP14 and HNF1A. Clin Epigenetics. 2019;11(1):186. https://doi.org/10.1186/s13148-019-0786-y.

48. Jiang H, Cao HJ, Ma N, Bao WD, Wang JJ, Chen TW, et al. Chromatin remodeling factor ARID2 suppresses hepatocellular carcinoma metastasis via DNMT1-snail axis. Proc Natl Acad Sci U S A. 2020;117(9):4770-80. https://doi.org/10.1073/pnas.1914937117.

49. Mishima Y, Brueckner L, Takahashi S, Kawakami T, Otani J, Shinohara A, et al. Enhanced processivity of Dnmt 1 by monoubiquitinated histone $\mathrm{H} 3$. Genes Cells. 2020;25(1):22-32. https://doi.org/10.1111/gtc.12732.

50. Wang J, Hevi S, Kurash JK, Lei H, Gay F, Bajko J, et al. The lysine demethylase LSD1 (KDM1) is required for maintenance of global DNA methylation. Nat Genet. 2009:41(1):125-9. https://doi.org/10.1038/ng.268.

51. Li J, Wang R, Hu X, Gao Y, Wang Z, Li J, et al. Activated MEKJERK pathway drives widespread and coordinated overexpression of UHRF1 and DNMT1 in cancer cells. Sci Rep. 2019;9(1):907. https://doi.org/10.1038/ s41598-018-37258-3.

52. Liu Y, Mayo MW, Nagji AS, Smith PW, Ramsey CS, Li D, et al. Phosphorylation of RelA/p65 promotes DNMT-1 recruitment to chromatin and represses transcription of the tumor metastasis suppressor gene BRMS1 Oncogene. 2012;31(9):1143-54. https://doi.org/10.1038/onc.2011.308.

\section{Publisher's Note}

Springer Nature remains neutral with regard to jurisdictional claims in published maps and institutional affiliations.
Ready to submit your research? Choose BMC and benefit from:

- fast, convenient online submission

- thorough peer review by experienced researchers in your field

- rapid publication on acceptance

- support for research data, including large and complex data types

- gold Open Access which fosters wider collaboration and increased citations

- maximum visibility for your research: over $100 \mathrm{M}$ website views per year

At BMC, research is always in progress.

Learn more biomedcentral.com/submissions 